\title{
Rotating Rig Development for Droplet Deformation/Breakup and Impact Induced by Aerodynamic Surfaces
}

A. Feo

Instituto Nacional de Técnica Aeroespacial, Madrid, Spain

M. Vargas

Glenn Research Center, Cleveland, Ohio

A. Sor

Instituto Nacional de Técnica Aeroespacial, Madrid, Spain 


\section{NASA STI Program . . . in Profile}

Since its founding, NASA has been dedicated to the advancement of aeronautics and space science. The NASA Scientific and Technical Information (STI) program plays a key part in helping NASA maintain this important role.

The NASA STI Program operates under the auspices of the Agency Chief Information Officer. It collects, organizes, provides for archiving, and disseminates NASA's STI. The NASA STI program provides access to the NASA Aeronautics and Space Database and its public interface, the NASA Technical Reports Server, thus providing one of the largest collections of aeronautical and space science STI in the world. Results are published in both non-NASA channels and by NASA in the NASA STI Report Series, which includes the following report types:

- TECHNICAL PUBLICATION. Reports of completed research or a major significant phase of research that present the results of NASA programs and include extensive data or theoretical analysis. Includes compilations of significant scientific and technical data and information deemed to be of continuing reference value. NASA counterpart of peer-reviewed formal professional papers but has less stringent limitations on manuscript length and extent of graphic presentations.

- TECHNICAL MEMORANDUM. Scientific and technical findings that are preliminary or of specialized interest, e.g., quick release reports, working papers, and bibliographies that contain minimal annotation. Does not contain extensive analysis.

- CONTRACTOR REPORT. Scientific and technical findings by NASA-sponsored contractors and grantees.
- CONFERENCE PUBLICATION. Collected papers from scientific and technical conferences, symposia, seminars, or other meetings sponsored or cosponsored by NASA.

- SPECIAL PUBLICATION. Scientific, technical, or historical information from NASA programs, projects, and missions, often concerned with subjects having substantial public interest.

- TECHNICAL TRANSLATION. Englishlanguage translations of foreign scientific and technical material pertinent to NASA's mission.

Specialized services also include creating custom thesauri, building customized databases, organizing and publishing research results.

For more information about the NASA STI program, see the following:

- Access the NASA STI program home page at http://www.sti.nasa.gov

- E-mail your question to help@sti.nasa.gov

- Fax your question to the NASA STI Information Desk at 443-757-5803

- Phone the NASA STI Information Desk at 443-757-5802

- Write to: STI Information Desk NASA Center for AeroSpace Information 7115 Standard Drive Hanover, MD 21076-1320 


\section{Rotating Rig Development for Droplet Deformation/Breakup and Impact Induced by Aerodynamic Surfaces}

A. Feo

Instituto Nacional de Técnica Aeroespacial, Madrid, Spain

M. Vargas

Glenn Research Center, Cleveland, Ohio

A. Sor

Instituto Nacional de Técnica Aeroespacial, Madrid, Spain

Prepared for the

International Conference on Aircraft and Engine Icing and Ground Deicing sponsored by SAE International

Chicago, Illinois, June 13-17, 2011

National Aeronautics and

Space Administration

Glenn Research Center

Cleveland, Ohio 44135 


\section{Acknowledgments}

The authors wish to express their gratitude to Tom Bond, formerly Icing Branch Chief of NASA Glenn Research Center and presently at the FAA, for his support, interest and prominent role played at the start of the new facility development. They also wish to thank all the technical personnel in the INTA Experimental Aerodynamics Department for their contributions to the facility development, and in particular to Juan Canales for his excellent work and dedication during many years to the Facility improvement, to Eva Jarillo for her continuous commitment and contributions to the droplet generation system and measurement procedures implemented at the facility, to J. Carlos Martín for his excellent work on the implementation of all the electrical systems needed, to Lorenzo Plana for his lighting, optics and single imaging contributions preparing the way for future advances in this area and finally to Francisco Rogles for his work and continuous improvements on the droplet/model synchronization established in the facility. Thanks to Dr. Peter Struk for reviewing the paper. Special recognition to NASA Glenn Research Center imaging specialists Christopher Lynch and Quentin Schwinn for their contribution to high-speed video imaging that can be used for future applications in this field.

Trade names and trademarks are used in this report for identification only. Their usage does not constitute an official endorsement, either expressed or implied, by the National Aeronautics and Space Administration.

Level of Review: This material has been technically reviewed by technical management.

Available from

NASA Center for Aerospace Information 7115 Standard Drive Hanover, MD 21076-1320
National Technical Information Service 5301 Shawnee Road Alexandria, VA 22312 


\title{
Rotating Rig Development for Droplet Deformation/Breakup and Impact Induced by Aerodynamic Surfaces
}

\author{
A. Feo \\ Instituto Nacional de Técnica Aeroespacial \\ 28034 Madrid, Spain \\ M. Vargas \\ National Aeronautics and Space Administration \\ Glenn Research Center \\ Cleveland, Ohio 44135 \\ A. Sor \\ Instituto Nacional de Técnica Aeroespacial \\ 28034 Madrid, Spain
}

\begin{abstract}
This work presents the development of a Rotating Rig Facility by the Instituto Nacional de Técnica Aeroespacial (INTA) in cooperation with the NASA Glenn Research Center. The facility is located at the INTA installations near Madrid, Spain. It has been designed to study the deformation, breakup and impact of large droplets induced by aerodynamic bodies. The importance of these physical phenomena is related to the effects of Supercooled Large Droplets in icing clouds on the impinging efficiency of the droplets on the body, that may change should these phenomena not be taken into account. The important variables and the similarity parameters that enter in this problem are presented. The facility's components are described and some possible set-ups are explained. Application examples from past experiments are presented in order to indicate the capabilities of the new facility.
\end{abstract}

\subsection{Introduction}

In-flight observations by pilots of large droplets breaking up when approaching lifting surfaces (Ref. 1) indicate the need to conduct studies of supercooled large droplets (SLD) break-up near large air transport airfoils, since modifications of cloud impinging efficiency would change the accreted ice mass and shape and therefore affect the aerodynamic performance of the aircraft.

Droplet deformation and breakup has been the subject of experimental research for many different applications. The type of disturbance defines how deformation makes progress and finally breaks up. Specific experimental tools have been used depending on the application and the objectives sought. In shock tubes used for high-speed gas streams and shockwave studies (Refs. 2 to 12), the droplet time-dependent deformation is dictated mainly by the location of the release and the magnitude of the disturbance. Wind tunnels have been used for lower speed studies, with droplets injected at different spatial locations and directions with respect to the air stream (Refs. 13 to 16). Recently, more wind tunnel studies have been performed with models included in the test section (Refs. 17 and 18). In this experimental configuration the parameters that may affect the deformation/breakup process are not only the ones related to their injection, but also include wind tunnel turbulence intensity and model/wall interference that become important for model/test section area ratios above 10 percent. Furthermore, to improve experimental simulation, it might be needed to measure droplet water temperatures and even to approximate their value to the ones existing in nature.

Past experimental studies of droplet deformation indicate that the last part after the deformation /breakup process may lead to different outcomes. One possibility is for the distorted droplet to hit the body surface with all of its mass. A second situation is when the droplet disintegrates into a fine micronsize spray before hitting the body, of which none, some or all may impinge onto the body. A third possibility is when part of the distorted droplet remains as a water mass that strikes the surface and the rest is converted into a fine spray of which again, none, some or all may re-impinge on the body surface. For the water mass striking the surface, some remains on the surface, while the rest splashes back into the air flow. This is the well-known splashing phenomenon that has been extensively studied in the literature for spherical shapes and many different values of the parameters that dominate the impact. However, for other shapes there is no information in the public domain. Wright and Potapczuk (Ref. 19) have reported on a number of empirical splashing models from existing experiments (Refs. 20 and 21) with an upper limit of $340 \mu \mathrm{m}$ and velocities of $30 \mathrm{~m} / \mathrm{s}$. The results shown from two of the empirical models for droplets of 21 and $91 \mu \mathrm{m}$ offer good comparisons with experimental collection efficiencies near the leading edge of the airfoil, but degrade towards the impinging limits. For droplets of $240 \mu \mathrm{m}$ there are no collection efficiencies to compare with, but the results of the two models used do not agree between themselves except on the impinging limits. This indicated the need for additional experimental work on splashing by large droplets. Studies (Ref. 22) on single droplet impacts in a vertical wind tunnel 
for droplets between 120 to $160 \mu \mathrm{m}$ and velocities of 20 to $100 \mathrm{~m} / \mathrm{s}$ impacting on thin water films, reported difficulties on the estimation of secondary droplet diameters, velocities and spreading diameters resulting from the impact. The droplet breakup and splashing dynamics for the mentioned complex phenomena need to be understood and measured in improved testing facilities and experimental configurations.

In the mid-1980s, INTA developed a small low power Rotating Arm Facility as part of a research effort in cooperation with NASA Langley Research Center on Heavy Rain on Aerodynamics of Aircrafts, to study the splash characteristics of typical spherical drops that are present in heavy rain events. The arm and model used were of small size, just enough to accommodate the drop impacts and determine the variables of the splash that dominate the phenomenon. The maximum model velocity was $60 \mathrm{~m} / \mathrm{s}$ and drop incidences were changed from near zero to perpendicular (Refs. 23 to 25). Additional development of the facility continued in 2007 as part of a Space Act Agreement research cooperation with NASA Glenn Research Center on Icing Physics, to offer capabilities for the study of supercooled large droplets (SLD) in icing cloud encounters that are subject to deformation/ breakup and possibly impact on the aircraft lifting surfaces. The design requirement for the model velocity was set to $90 \mathrm{~m} / \mathrm{s}$ and $0.5 \mathrm{~m}$ chord, so that the phenomena of interest had the possibility of being observed and measured (Ref. 26). The present work explains the development of the facility and its upgrading from the capabilities of droplet splashing to the droplet breakup experiments.

Potential advantages of facilities that allow experiments with moving models (e.g., rotating arms, acceleration tracks, etc.) include the following: smaller injection release effects on the droplet deformation/breakup stability; less uncertainty in droplet temperature when reaching the target area due to shorter trajectory, simpler droplet control to reach specific target locations; easier and more effective droplet visualization methods to follow droplets along their the trajectories.

In the following sections details are given on the development of the Rotating Rig. The section are: 2.0 Variables and parameters defining the experiments; 3.0 Detailed description of the facility; 4.0 Possible experimental set-ups; 5.0 Application examples; and 6.0 Concluding remarks.

\subsection{Problem Definition, Variables and Non-Dimensional Parameters}

The development and use of a unique facility such as the Rotating Arm Facility, expressly designed for experimental research in the field of large water droplets approaching aerodynamic surfaces in conditions similar to the ones encountered in flight, requires knowledge of the relevant physical magnitudes to prepare instrumentation and experimental techniques to be used. Due to the number of variables involved, the reduction and ordering of these variables in the form of non-dimensional groups of input and output parameters is appropriate.
There is not yet a comprehensive theory of large droplet behavior along the trajectories from far upstream to the body surface for the conditions existing in aircraft icing encounters. Initial experiments (Ref. 26) showed that during the deformation process, the droplet presents a continuous geometric change from spherical to ellipsoidal and finally into a flattened disk without any mass loss. The droplet's breakup may be considered to be the last part of the deformation process. At this point, a transformation starts into clearly distinctive units such as water membranes, secondary droplets, water rings, etc., depending upon the breakup regime (bag, shear or catastrophic). The facility has to be prepared to visualize and/or measure all the variables involved in the phenomena and determine what are the dominant parameters to understand the physical phenomena that take place for different input conditions. An initial assessment of the number of variables and non-dimensional parameters that may influence the final characteristics of the several phenomena that appear can be done based on previous experimental results and on dimensional analysis. In the next paragraphs the main variables and non-dimensional parameters that need to be measured in the facility are presented.

Droplet size is a key variable for trajectory determination in aircraft icing conditions. There are three groups of diameters presenting distinctive behavior as far as trajectories are concerned. The first is for submicron diameters that basically follow the air streamlines and present no problem in trajectory calculations. The second is for droplets between 10 and $50 \mu \mathrm{m}$ that are included in Appendix $\mathrm{C}$ regulations and their trajectories are calculated assuming that they behave as solid spheres. The third is for diameters from 50 to $3000 \mu \mathrm{m}$ and are the so called "Supercooled Large Droplets" that include freezing drizzle and freezing rain. For these droplets, the aerodynamic forces tend to distort their spherical shape and may even induce them to breakup. Droplets in these situations could end up impacting the body depending on conditions.

A body moving at constant velocity through still air determines a flow field which is a function of the following variables: $U$ being the incoming free stream air velocity magnitude respect to a frame of reference fixed at the body; $\rho$ the air density, $\mu$ the air viscosity coefficient and $c$ a characteristic body length. Should other dimensions be needed to define the body geometry, they would be made nondimensional with respect to $c$. Also, the body attitude with respect to the path may be another variable, but for simplicity will not be considered here. The air velocity at any point in the field $U$ is then a function of $U_{a}=f(U, \rho, \mu, c)$. Dimensional analysis yields:

$$
\frac{U_{a}}{U}=f\left(\frac{\rho U c}{\mu}\right)
$$

Where $U_{a}$ is the air velocity and $(\rho \cdot U \cdot c / \mu)$ is the Reynolds number based on the characteristic length $c$.

The droplet's motion through the air velocity field, at any point with air velocity $U_{a}$ is a function of the following 
variables: $d$ the diameter of the droplet; $x_{d}$ is the distance from the droplet to the body; $t_{d}$ is the time it takes the droplet to get to the body; $U_{d}$ is the droplet's velocity magnitude; $a_{d}$ is the droplet's acceleration magnitude, $\sigma_{w / a}$ is the water/air surface tension, $\rho_{w}$ is the water density, and $\mu_{w}$ is the water viscosity coefficient. For convenience, the magnitude of the relative air/droplet velocity $U_{d r}$ may be used instead of $U_{d}$ in some of the parameters. The same can be said for the droplet relative air/velocity acceleration $a_{d r}$. Any of the resultant characteristics (e.g., deformation geometry, secondary droplet diameter, etc.) denoted by $C$, as part of the deformation, breakup or impact is a function of:

$$
C=f_{d}\left(d, x_{d}, t_{d}, U_{d r}, a_{d}, \sigma_{w / a}, \rho_{w}, \mu_{w}, U, c, \rho, \mu\right)
$$

Dimensional analysis yields:

$$
\begin{aligned}
& C_{\text {non-dimensional }}= \\
& F_{d}\left(\frac{d}{c}, \frac{x_{d}}{c}, \frac{t_{d} U_{d r}}{c}, \frac{\rho U_{d r} d}{\mu}, \frac{\rho U_{d r}^{2} d}{\sigma_{w / a}}, \frac{\rho_{w} d^{2} a_{d}}{\sigma_{w / a}}, \frac{\mu_{w}}{\mu}, \frac{\rho_{w}}{\rho}, \frac{\rho U c}{\mu}\right)
\end{aligned}
$$

Where $\frac{\rho U_{d r}^{2} d}{\sigma_{w / a}}$ is the Weber number, $\frac{\rho_{w} d^{2} a_{d}}{\sigma_{w / a}}$ is the Bond number, and $\frac{\rho U_{d r} d}{\mu}$ and $\frac{\rho U c}{\mu}$ are the Reynolds numbers.

In the case that some water mass hits the body surface after the deformation/breakup process, it will need to be experimentally determined how much of the water will splash back, what its characteristics will be and how the rest of the water mass will be deposited on the body surface. The splashing process is governed by the following variables: the equivalent droplet diameter $d_{e}$; the impact velocity $U_{i}$; the water film thickness on which the impact takes place $h$; the surface roughness $\delta_{r}$; the time elapsed since the start of the splashing process $t_{s}$; the water density $\rho_{w}$; the water viscosity coefficient $\mu_{w}$; the water/air surface tension $\sigma_{w / a}$; and the water/surface contact angle $\theta$.
Thus, any splash characteristic $C_{s}$, is a function of:

$$
C_{s}=f_{d}\left(d_{e}, U_{i}, h, \delta_{r}, t_{s}, \rho_{w}, \mu_{w}, \sigma_{w / a}, \theta\right)
$$

Dimensional analysis yields:

$$
C_{S \text { non-dimensional }}=F_{s}\left(\frac{\rho_{w} U_{i} d_{e}}{\mu_{w}}, \frac{\rho_{w} U_{i}^{2} d_{e}}{\sigma_{w / a}}, \frac{h}{d_{e}}, \frac{\delta_{r}}{d_{e}}, \frac{t_{s} U_{i}}{d_{e}}, \theta\right)
$$

Where $\frac{\rho_{w} U_{i}^{2} d_{e}}{\sigma_{w / a}}$ is the Weber number and $\frac{\rho_{w} U_{i} d_{e}}{\mu_{w}}$ the Reynolds number.

In droplet breakup and splashing experiments the main parameters measured or calculated are the Weber number, the Bond number and the Reynolds number.

\subsection{Facility Description}

The previous sections explained the need for experiments showing visualization/observation with measurements of large droplet behavior along the trajectory upstream of bodies that simulate lifting surfaces of large transport aircraft in flight. To accomplish this objective, the Rotating Rig Facility developed initially for splashing experiments was upgraded to move an aerodynamic body with a characteristic length of at least $0.5 \mathrm{~m}$ to a velocity up to $90 \mathrm{~m} / \mathrm{s}$. The range of droplet generation was increased from 100 to $3000 \mu \mathrm{m}$. Digital techniques using state of the art high speed camera and video equipment were added for observations and measurements. Varying the parameters, enough data can be generated to understand the general problem, with conclusions for the full scale through analytical calculations and/or data extrapolation. Additional modifications to the facility consisted in the modification of critical components, starting with improvements required for safety reasons in the room housing the Facility due to increased arm and model dimension as well as the maximum velocity of operation (Figure 1) (Ref. 27). The components and equipment that have been upgraded or added are described below.

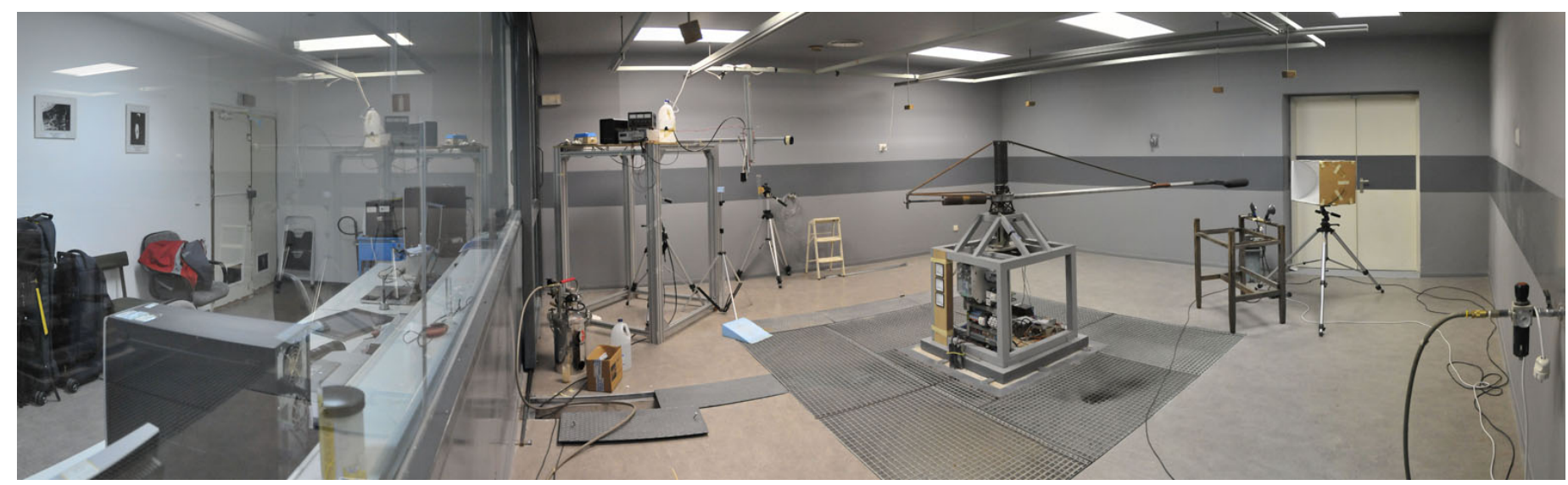

Figure 1.-General view of the Rotating Rig Facility. 


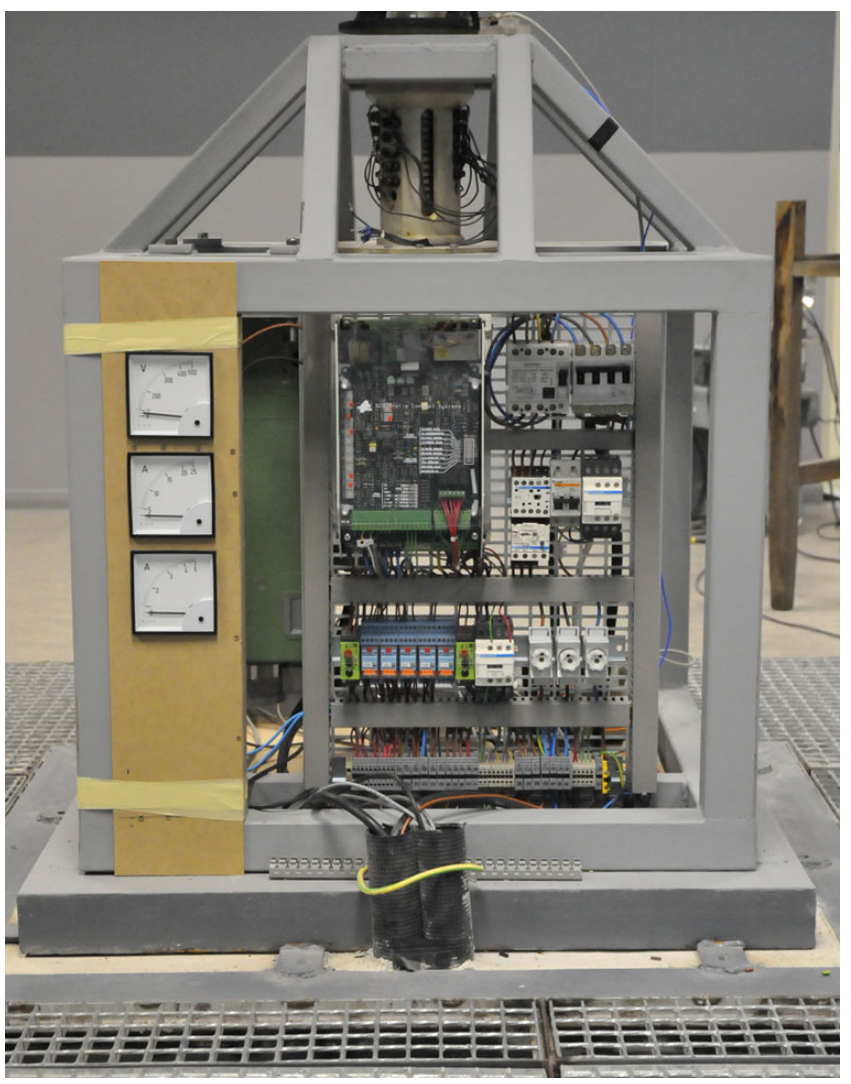

Figure 2.-Rotating Rig Support Structure.

\subsection{Support Structure}

A new structure has been designed to comply with the requirements of increasing the model velocity to $90 \mathrm{~m} / \mathrm{s}$, the dimension to $0.5 \mathrm{~m}$ and the arm length over $2 \mathrm{~m}$. For the maximum nominal velocity and model size, the maximum vibration detected by an accelerometer attached to the structure must remain below a pre-determined value for which an electric brake is actuated to stop the rotation. The structure is built with hollow steel beams of square cross section with the shape of a cube of $0.86 \mathrm{~m}$ on the lower side and of a truncated pyramidal shape of $0.28 \mathrm{~m}$ height on top (Figure 2). The structure is welded to a steel plate attached to a concrete block on the floor. Internally the structure houses a new 5.0 KW DC Electric Motor with forced ventilation and temperature sensor to disconnect the electric supply in case of overheating; the electronic control system; the transmission gears; the 12 channels slip rings unit and the vertical axle connected to the arm's head (Figure 3).

\subsection{Arm and Counterbalance}

The velocity increase and the larger model made it necessary to redefine the arm radius and its cross section. The main consideration when increasing the arm length was to decrease the centrifugal forces on the model. Increasing the

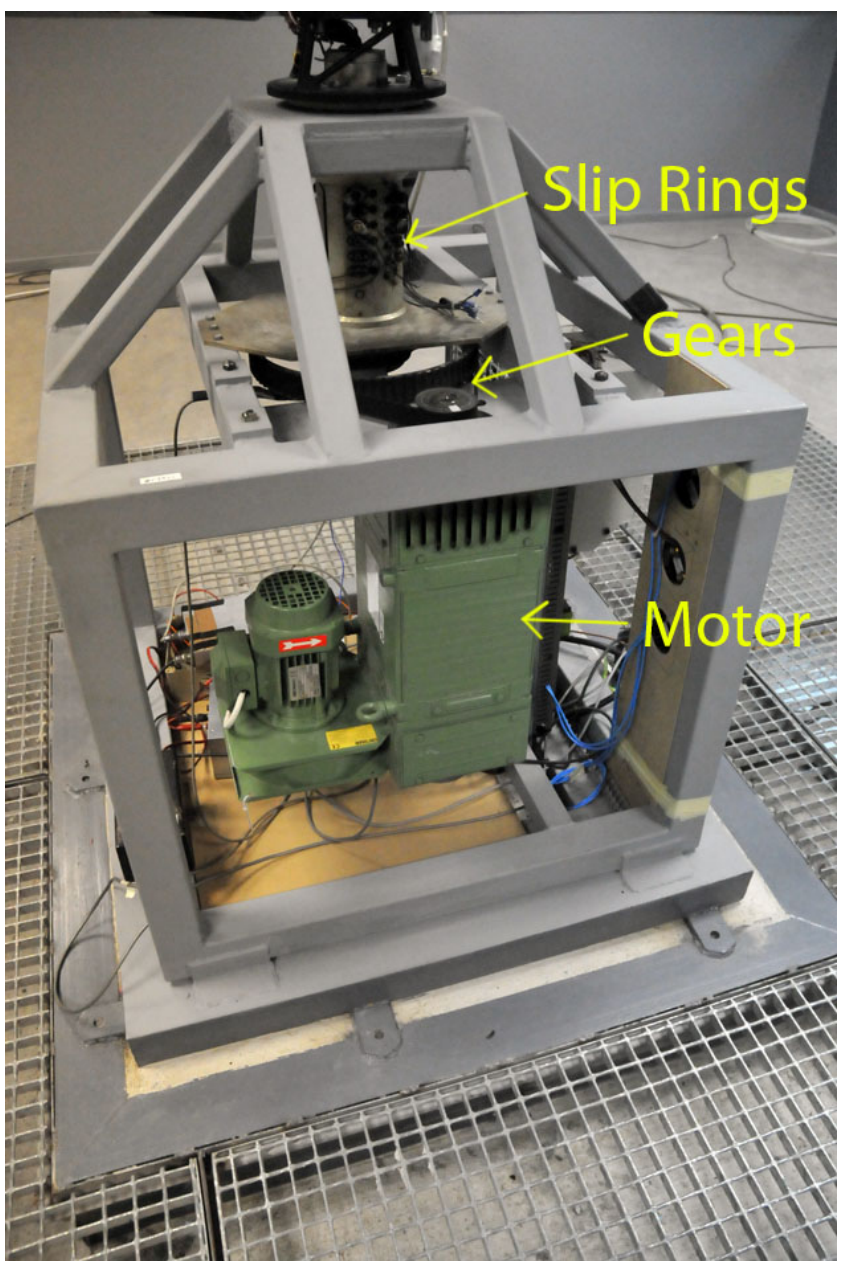

Figure 3.-Rotating Rig Support Structure, Internal View.

arm length has the added benefit of a smaller aerodynamic wake effect from the previous rotation, to the point that it may be neglected in the study of droplet deformation /breakup and impact intended for this Facility. The arm material was changed to aluminum, incorporating a streamlined cross section of $0.09 \mathrm{~m}$ chord and a length of $2.16 \mathrm{~m}$ from the rotation axle to the arm tip. The new conditions made the counterbalance weight and position critical when performing balancing of the model/arm operation. Small counterbalance variations gave large changes on the balance of the model/arm. Both the arm and counterbalance had to be supplemented with struts, to increase the unit stiffness and decrease horizontal and vertical vibrations (Figure 4).

\subsection{Models}

The model is one of the most important components of the rotating rig facility. Mechanical and aerodynamic elements enter in its design. Due to the large centrifugal forces present, the mass needs to be carefully adjusted to the possible minimum, selecting the appropriate low density material supplemented with light metallic materials of enough 


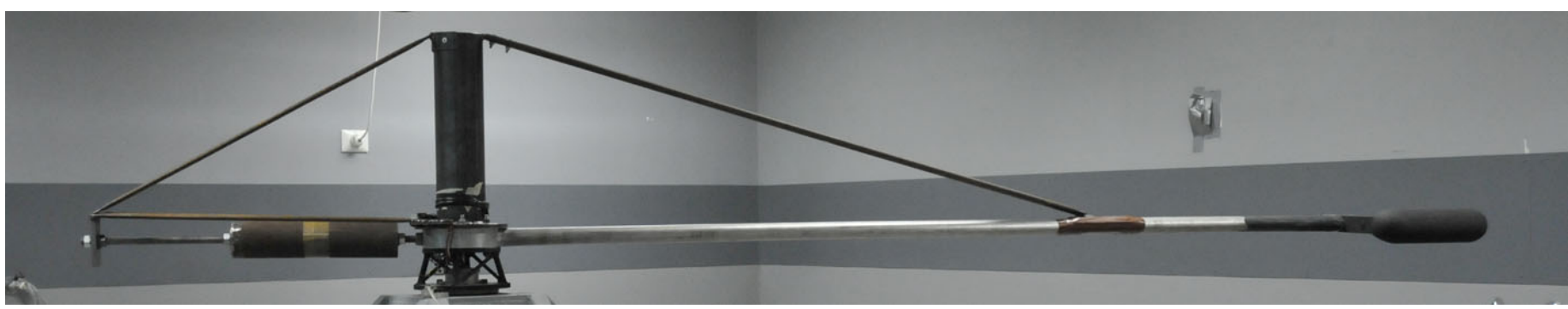

Figure 4.-Rotating Rig Arm and Counterbalance.

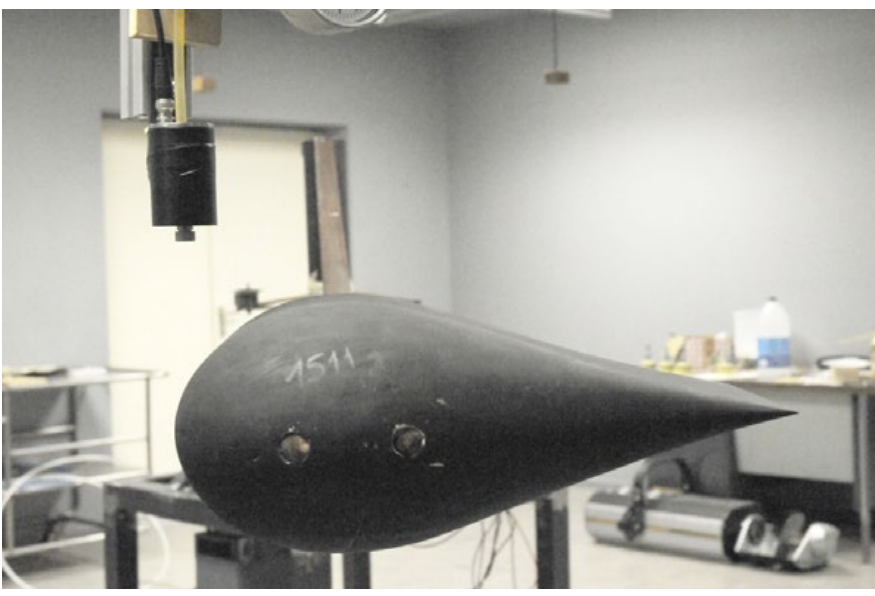

Figure 5.-DBKUP 002 Model with $0.47 \mathrm{~m}$ chord and $0.35 \mathrm{~m}$ span.

structural strength in the model interior to maintain its integrity and sustain the union to the arm. Another important aspect in relation with the intended simulation in the experiments is the aerodynamic design. The air flow forces need to be maintained low so that the required velocity can be attained, considering the power constraints imposed by the electric motor and keeping the associated aerodynamic wake effects to the minimum. An example of model design is the one shown in Figure 5, which is the DBKUP 002 model that was used in the observation experiments reported in Reference 26. It is a small aspect ratio wing with $0.47 \mathrm{~m}$ chord and $0.35 \mathrm{~m}$ span with a large airfoil thickness, to simulate as much as possible the one found on the leading edge of a large transport aircraft wing. It was required as part of model design to mount an accelerometer in its interior to detect undesired vibrations.

\subsection{Mono-Disperse Droplet Generator}

Mono-disperse droplet generators operate through vibration of a water jet coming out of a circular orifice (Figure 6). If a laminar liquid jet with a flow rate $Q$ is vibrated at frequency $f$, it produces at short distances from the orifice an equally spaced stream of droplets that follow the expression (Ref. 28):

$$
d(\mu \mathrm{m})=317(Q(\mathrm{cc} / \mathrm{min}) / f(\mathrm{kHz}))^{1 / 3}
$$

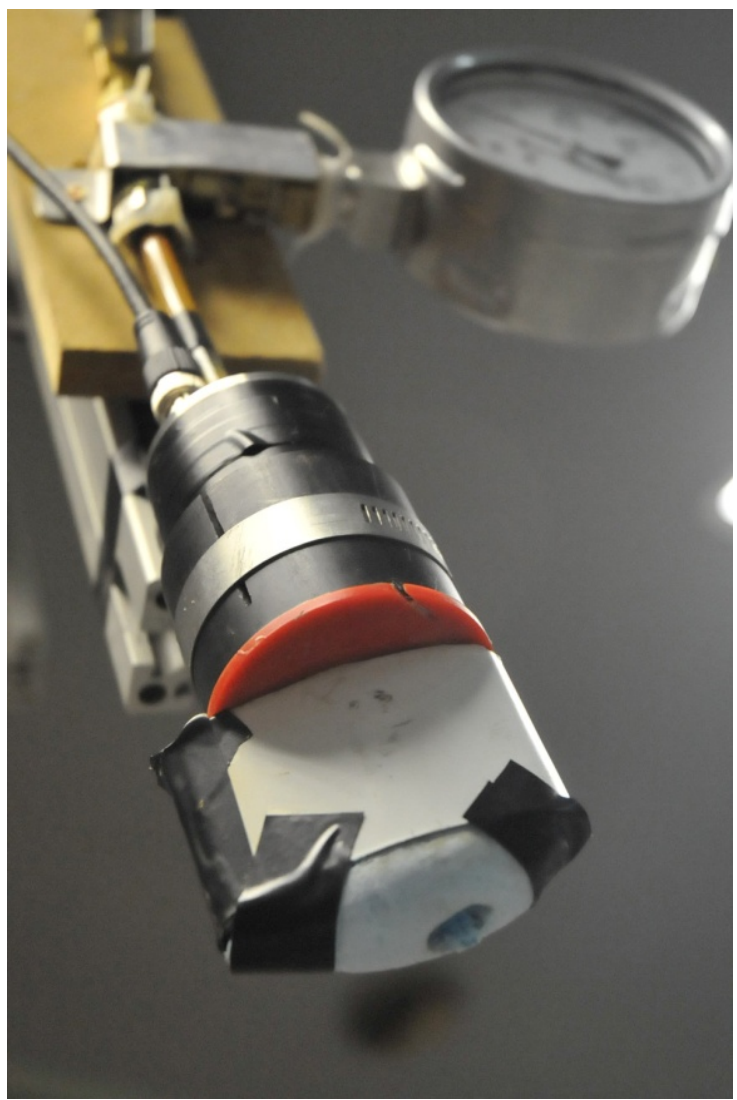

Figure 6.-Droplet Generator with Aerodynamic Protection.

The range of droplet sizes for a fixed orifice diameter is limited by the liquid jet velocity that stays in the laminar regime, indicating the limit of operation for that orifice. To increase the range of droplet diameters, larger orifice diameters need to be used. There is a group of frequencies (Raleigh frequencies) that follow the expression (Ref. 28):

$$
f_{R}=U_{j} / 4.508 D_{j}
$$

where $U_{j}$ is the water jet exit velocity and $D_{j}$ is the jet diameter (assumed to be equal to the orifice diameter), that produce a longer stable stream of droplets with diameter approximately twice the jet diameter (Figure 7). The basic system consists of a stainless steel water pressure container, connected through 


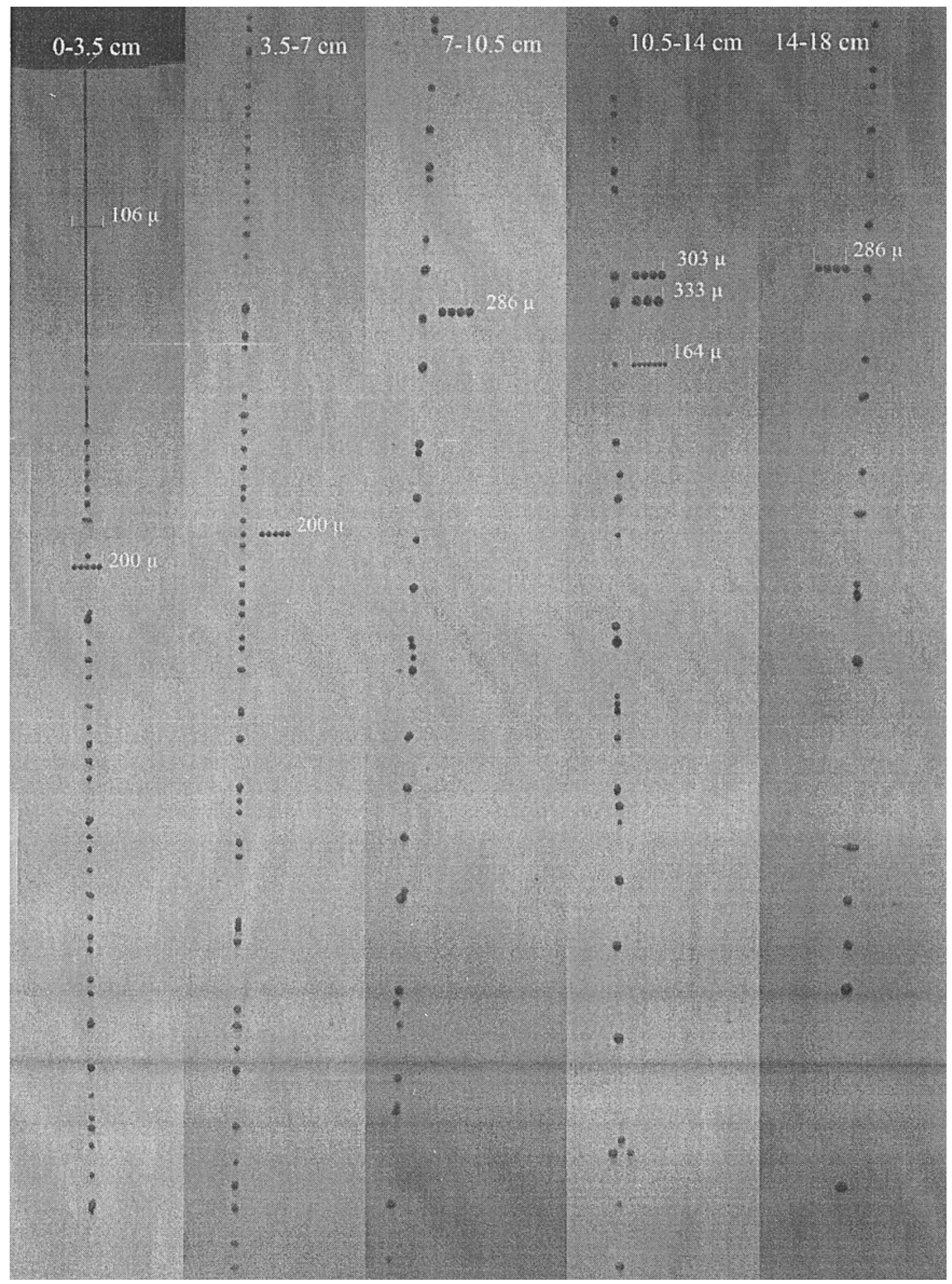

Figure 7.-Stream of Droplets. Orifice diameter $100 \mu \mathrm{m} ; . f_{R}=20.7 \mathrm{KHz}$; flow rate $4.5 \mathrm{cc} / \mathrm{min}$. Droplets at different distances from orifice. 
plastic tubing to a precision control valve with a manometer, to supply constant water pressure to the vibrating head directed to the exit orifice. The frequency generator prepared for this application was a $5 \mathrm{MHz} B \& \mathrm{~K}$ Precision model 4011A. While in operation with the arm and model in rotation, an aerodynamic protector can be attached to the vibration head orifice exit to minimize external air disturbances that may promote premature breakup of the water jet into undesirable droplet sizes before it gets into the flow field induced by the model.

\subsection{Lighting}

Lighting equipment is another of the essential elements of the facility. The lighting instrumentation requirements are imposed by higher velocities and smaller droplets. Depending on the test objectives, high-intensity-continuous or shortduration lights may be used. For droplet breakup and impact research experiments, the minimum time required is in the order of microseconds and the equipment used should be prepared to supply high intensity light during that order of magnitude or less. If the tests require high-speed video equipment, frame rates from 50,000 to 150,000 per second would be needed with high-intensity lighting to capture images in sufficient resolution. Different lighting configurations that have been used include: direct parallel light rays to the object (Shadowgraphy), parabolic reflectors, and diffusing paper. For general type observation images, simple direct backlight was used to satisfy the requirement. Examples of the equipment that have been used to provide short duration lighting include: Strobotac $3 \mu$ sec lamp with single or double variable time delay exposure; Microflash with microsecond spark; Nanoflash with nanosecond spark. For continuous lighting a xenon $2000 \mathrm{~W}$ lamp was used.

\subsection{Imaging}

Visualization is the basic technique in the Facility, from which measurements have to be obtained and interpreted to analyze the phenomena under consideration and characterize it quantitatively. The single short duration lights need synchronization and time-delay systems connected to the camera in order to capture the images. Due to the small droplet sizes involved, care must be exercised in choosing the appropriate high quality lens, extension rings and magnification to achieve maximum resolution compatible with reasonable field of view, to permit measurement and analysis of the pertinent characteristics. The same considerations apply to high-speed video, adding frame rate selection, total number of frames and synchronization of the starting frame with model location. An example of equipment used for single image cases is a Hasselblad digital camera Model H3 39 with lens and extension rings that permit a field of view of 35- by $25-\mathrm{mm}$ with a resolution of 131 pixels per $\mathrm{mm}$, at a distance from the object of $0.6 \mathrm{~m}$. Equipment for the high-speed video include a Photron SA 5 high speed camera used at frame rates from 50,000 to 150,000 with a $200 \mathrm{~mm}$ Micro Nikkor lens and a 2 plus doubler at distances from the object from 0.91 to $0.36 \mathrm{~m}$.

\subsection{Additional Support Instrumentation}

Variables related to the air motion due to model rotation and others like the breakup secondary droplet characteristics cannot be measured with the visualization tools mentioned in previous paragraphs. The air velocity outside the model's path may be measured with conventional pressure probes to understand the air rotation inside the closed room including the wall effects. Measurements along the model's path while in rotation must be done with non-intrusive techniques, such as Laser Doppler Velocimetry (LDV) or Particle Image Velocimetry (PIV) to determine model rotation upstream and downstream wake effects. To complete the study of model rotation effects, model surface pressure measurements may be required. This is done through ordinary pressure taps with transducers transmitting signals through the slip rings or telemetry with direct transmission to the data acquisition room. For characteristics of secondary droplet determination, resulting from either the breakup or impact processes, high resolution image technology or Phase Doppler Particle Analyzer (PDPA), traversing a pre-determined control volume, may be needed to obtain droplet size distributions.

\subsection{Experimental Set-Ups}

Depending of the objectives of the tests, different experimental set-ups may be used in the Facility. Three main test categories can be considered: 4.1 Calibration of the facility; 4.2 Droplet deformation and breakup; and 4.3 Surface droplet impact.

\subsection{Calibration of the Facility}

Because of the rotating nature of the experiments, some preliminary tests need to be made to find the limits for each particular application. The model's mean linear velocity and its standard deviation over a number of turns need to be measured. Instrumentation includes an opto-switch which captures light to be transmitted as an electric signal to an electronic time delay board, installed to trigger a microsecondduration high intensity light, into a parallel light conversion unit to obtain shadowgraph images that are to be captured on a digital camera for later processing. The opto-switch may be installed fixed to the structure near a rotating part that includes a reflector. The image plane of the camera must be oriented perpendicular to the straight line defined by the reflector center and the camera lens.

The model velocity is obtained from the arc length that the model traverses during the time delay. The time delay is initiated when the model is at the position where the opto- 
switch is triggered. At the end of the time delay the camera is triggered and the position of the model is captured. Repeating the process a number of times at the required velocity, a group of model velocities is obtained from which mean and time standard deviation may be calculated.

An important part in the calibration of the facility is the determination of air motion induced by the model after successive rotations. There are two different groups of measurements that are needed to see the limitations in size for a type of model due to the air motion induced by it.

- The first consists of measurements within the model path while it is in rotation, conducted at the section where the droplets are designed to be released or injected. The precise model location is required to correlate with an individual piece of data, and for that particular task synchronization is needed. The model's circular path can be described in three sections: approximately one chord upstream of the location where the droplets are released, approximately one chord downstream (near the wake) of the location where the drops are released, and the rest of the circular path. Non-intrusive instrumentation must be used to obtain reliable data for any of the three locations. A simple possibility is the use of a Backscatter 1-D Laser Doppler Velocimeter, with the control volume at the model centerline, directed on the circle's tangent and synchronized with the model position for any of the cases.

- The second includes measurements outside the model path along points located on a radial line (in the horizontal rotation plane) from the center of the arm rotation to the intersection with the location where the droplets cross the horizontal plane. The air motion at these locations (swirl) is influenced by the model position and subjected to interferences by the test cell room walls, floor and ceiling. The measurements need to be synchronized and correlated with the model position. Measurements were conducted with a PIV system and can be made also with intrusive conventional instrumentation such as total pressure probes.

These two groups of measurements, after being analyzed, may indicate whether the results obtained in a given experiment can be used directly for the intended purpose, or whether some type or correction is needed.

Other important aspects for calibration are the droplet size and velocity of release/injection, in conditions of use similar to the applications. Given a droplet generator with a fixed diameter orifice, the water flow rate and vibration frequency produce a droplet stream that at small distances from the orifice (in the order of 300 diameters) allows theoretical prediction of the droplet size. At greater distances from the orifice, coalescence of droplets begins to take place and the droplet diameter changes slowly with distance. Under these circumstances prediction of droplet diameter is no longer possible and calibration is needed.
A high-speed shadowgraph was used for calibration of the size of the droplets. In this method, a device calibrated by length (e.g., micrometer) is located where the droplet stream will appear. With the digital camera in the same position as in the tests, a correlation can be made between the pixels of the camera images and the size of the device used for the calibration. This gives the scale of the number of pixels per millimeter, which can then be applied to the corresponding tests. As a check for this type of calibration a Phase Doppler Particle Analyzer (PDPA) was used in a separate bench test (Ref. 29).

\subsection{Droplet Deformation and Breakup Processes}

Once the droplets are within the upstream aerodynamic influence induced by the body, external forces and internal reactions produce shape deformation and in some conditions may lead to different types of fragmentation (breakup process) that could result in a large number of very small secondary droplets. The facility needs to be prepared to measure all important physical characteristics of both deformation and breakup. The deformation process for the disturbance type and conditions of interest has a time range measured by the millisecond, and the instrumentation used must be capable of addressing this time constraint. To follow a droplet from the spherical to the flattened disk final shape, a high speed digital video camera is needed, with frame rates per second ranging from 50000 to 150000 and compatible with the acceptable field of view and resolution. The present state of the technology for these cameras limits the resolution as the frame rate increases. To modify the magnification, the camera needs to be placed at different distances from the object. The shutter exposure time needed is very short (about $1 \mu \mathrm{sec}$ ) making it necessary to use a high intensity continuous light directed through a diffusing paper and located behind the object to create shadow images on the camera.

Before the rotating arm is put into operation for a test, the camera needs to be aligned so that the line of sight through the lens towards the object coincides with the line that runs along the span of the model on the leading edge. The diffusing paper is placed perpendicular to that line of sight and the high intensity light is directed perpendicular to the paper. Synchronization of model position and starting time has to be defined, so that every single frame may be correlated with model location, since in most of the frames only the droplets will appear on the image.

Should the external conditions be appropriate, the droplet will be able to continue the deformation process at a faster rate with part of its mass concentrated in some particular locations and connected with the rest through a thin water membrane. This configuration of the droplet is very unstable and prone to disintegration into secondary droplets that are of much smaller size than the original droplet. At this point of total droplet disintegration, the breakup process is considered to have ended. 
All parts of the process need to be captured in images, from the extreme distortion into a flattened disk shape followed by the large deformation of the disk central region into a thin water membrane (bag type breakup), and ending in a spray of secondary droplets. For conditions that produce typical breakup in the rotating rig facility, the total time duration of the process has been observed to be in the range of 100 to $150 \mu \mathrm{sec}$. A highspeed video camera set up as explained earlier may be used. However, even with high frame rates, only a few frames are useful because of the camera technology limitations, and the resolution obtained is not optimal. To improve this situation, high-speed video images complemented with a series of single short duration exposure images synchronized with the model are used. The first part of the set-up is the definition of the minimum field of view needed to capture the phenomenon, including the model leading edge to correlate time with the state of the breakup. The camera should be aligned with the model leading edge (when it is located at the image center) and the source of the short duration light. The selected camera optics must achieve compatibility with the previously mentioned requirements, with sufficient resolution to measure the characteristics of the breakup.

\subsection{Surface Droplets Impacts}

The last phase of the deformation and breakup process ends with impact of the full droplet mass upon the surface, except for the case of total disintegration. In this case, depending on the droplet size distribution, the mass may not impact on the surface location where it was supposed to impinge but may re-impinge at a later time on other surface locations. The droplet shape of interest in impact research studies ranges from spherical to ellipsoidal to highly distorted shapes, each with different outcome characteristics. These impacts take place on wetted surfaces where the water film thickness is one of the most important variables to be measured. For the higher velocities, the time elapsed during a perpendicular impact is in the order of 5 to $50 \mu \mathrm{sec}$, for droplet diameters ranging from $100 \mu \mathrm{m}$ to $1 \mathrm{~mm}$. The difficulty in capturing images with acceptable resolution using high-speed video cameras makes the use of this type of equipment valid only as a complement to other measurements of the impact resultant characteristics. Due to the very short time involved in the impact process, the camera field of view is smaller than the one used for the droplet deformation and break up process, and the distance from the camera lens to the object is shorter.

The camera optics selected should be in accordance with the indicated conditions to offer maximum resolution. An important difference with the other processes is the ability to obtain 3D visualizations, created from two simultaneous views to capture the essential characteristics of the outcome. To capture two simultaneous images, two separate short duration light sources have to be positioned such as to produce a shadow (lateral image) and a plan view. Synchronization of droplet and model position is another distinctive feature that needs to be taken into account in studies of the impact process.

\subsection{Application Examples}

The following cases for application to droplet trajectories approaching a model are presented below: 5.1 Calibration of the Facility-Air Induced by the Model; 5.2 Droplet deformation and breakup; and 5.3 Droplet impact.

\subsection{Calibration of the Facility-Air Induced by the Model}

Some results are presented below on the air velocity induced within the model trajectory, made with non-intrusive laser instrumentation. A Particle Image Velocimetry System (PIV) was used. The results include a comparison with previous wind tunnel results made with a model of the same geometry along the stagnation line. The PIV System works by illuminating with a laser light sheet the air flow that has been previously seeded with micron size particles. Images of a double pulse of nanosecond duration each are recorded with a CCD camera. Correlation analysis is done to obtain the air velocity measurements. The model airfoil section used for this Calibration Program is the same as the one in Reference 26, but with a chord of $0.199 \mathrm{~m}$ and maintaining the same velocity of $90 \mathrm{~m} / \mathrm{s}$.

A light sheet has been generated in the vertical and horizontal planes with respect to the camera, which is located to record square fields of view of 200, 60 and $30 \mathrm{~mm}$ (Figure 8). Images are taken at different distances, from the model leading edge to the location where droplets are released in a droplet breakup experiment. An image captured with the vertical plane and field of view of 30 - by $30-\mathrm{mm}$ is shown in Figure 9. In this figure the leading edge of the airfoil is on the right side (rounded dark shadow). The stagnation streamline is located at about $y=-15 \mathrm{~mm}$. Small arrows indicate the direction of the velocity. The magnitude of the velocity is color coded. The lower velocities are shown in blue, the higher velocities in red.

The PIV system software has the capability to extract the air velocities. The air velocities (external reference axis) along the stagnation streamline, measured for three vertical fields of view, are plotted in Figure 10. Previously, wind tunnel measurements of velocities along the stagnation line were performed with a LDV system at $40 \mathrm{~m} / \mathrm{s}$ for a model of similar geometry and $0.047 \mathrm{~m}$ chord. This result is shown in Figure 11 (Ref. 30). The comparison between the velocities along the stagnation streamline measured with the PIV system in the rotating rig and the velocities measured with the LDV system in the wind tunnel is shown in Figure 12 (Ref. 31). The velocities in Figure 11 and Figure 12 are for a frame of reference located on the model. For this particular model the velocities agree well indicating no effect from the air motion induced by the model attached to the rotating arm. 


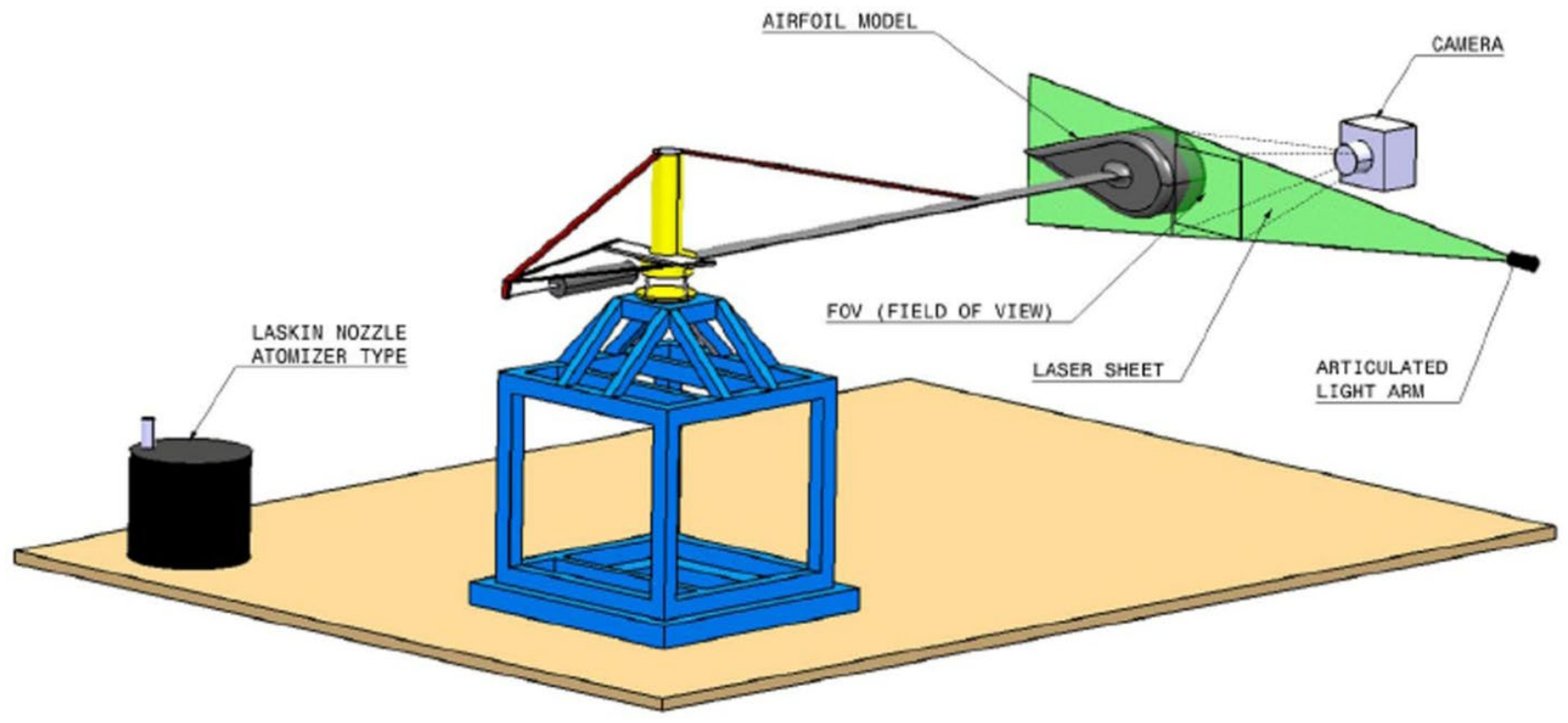

Figure 8.-Experimental setup. Vertical plane. From left to right: air flow seeding atomizer; rotating arm and model; PIV field of view, camera and light sheet plane.

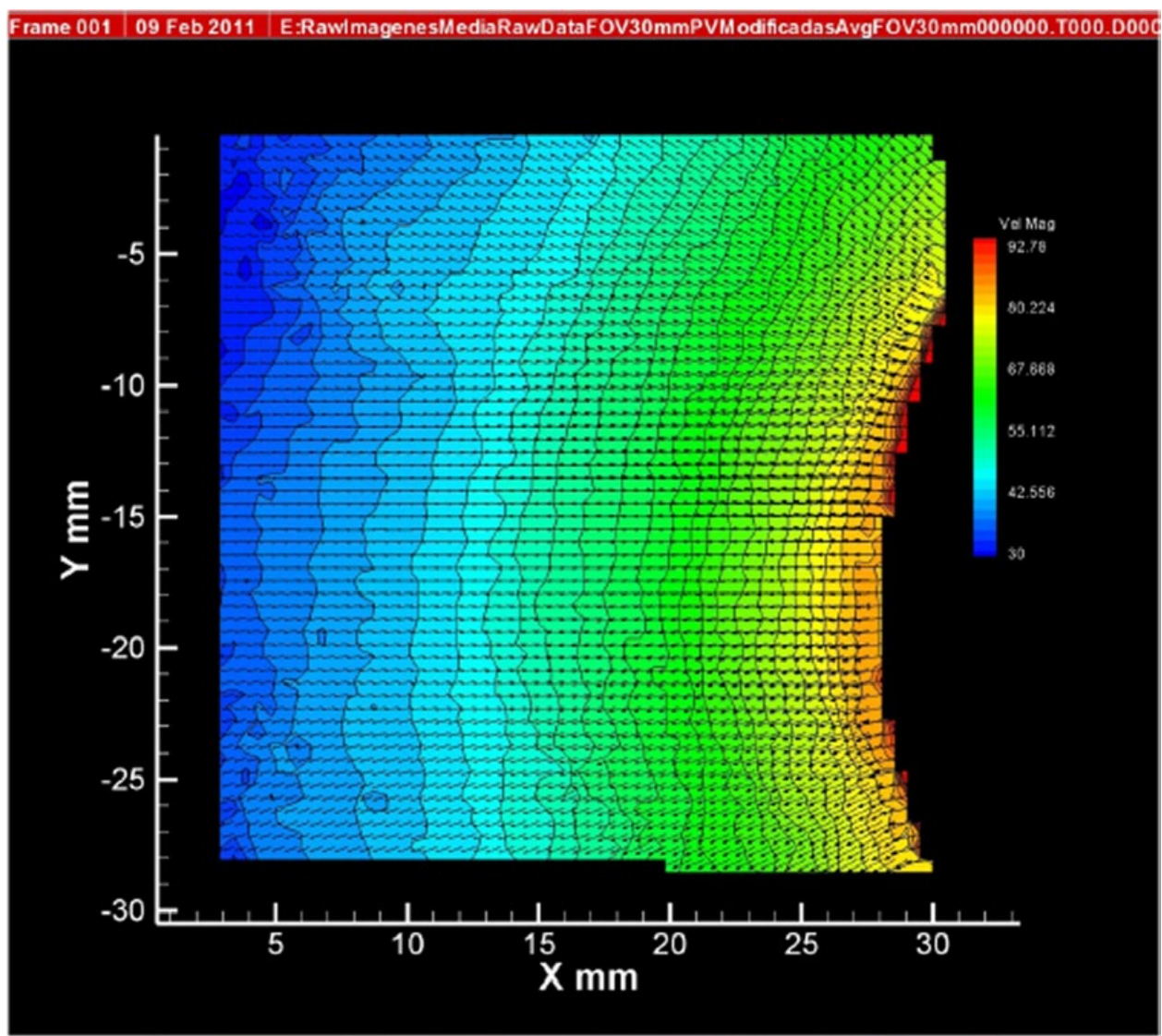

Figure 9.-Average of 10 pairs of images processed. Vertical plane. Field of view: $30-$ by $30-\mathrm{mm}$. From left to right: Isovelocity lines with lower values at left increasing to right; model leading edge in black with stagnation line perpendicular to model at approximate value $Y=-20 \mathrm{~mm}$; scale on right side from approximately $30 \mathrm{~m} / \mathrm{s}$ (lower blue) to $92 \mathrm{~m} / \mathrm{s}$ (higher red). 


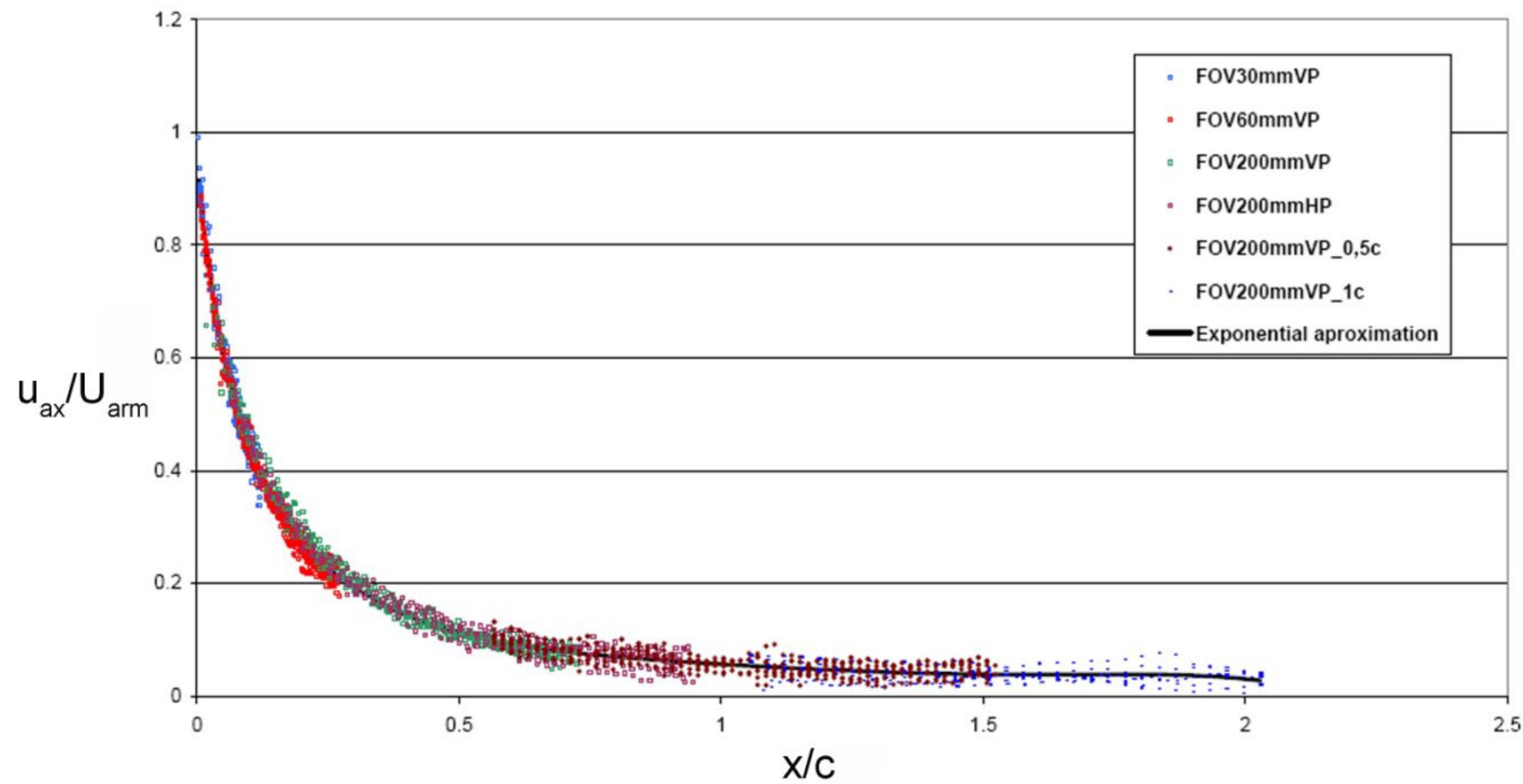

Figure 10.-PIV results along the stagnation streamline. Taken for different fields of view (FOV) on horizontal (HP) and vertical (VP) planes for model at 0.5 and 1.0 chords from leading edge to field left line (external reference).

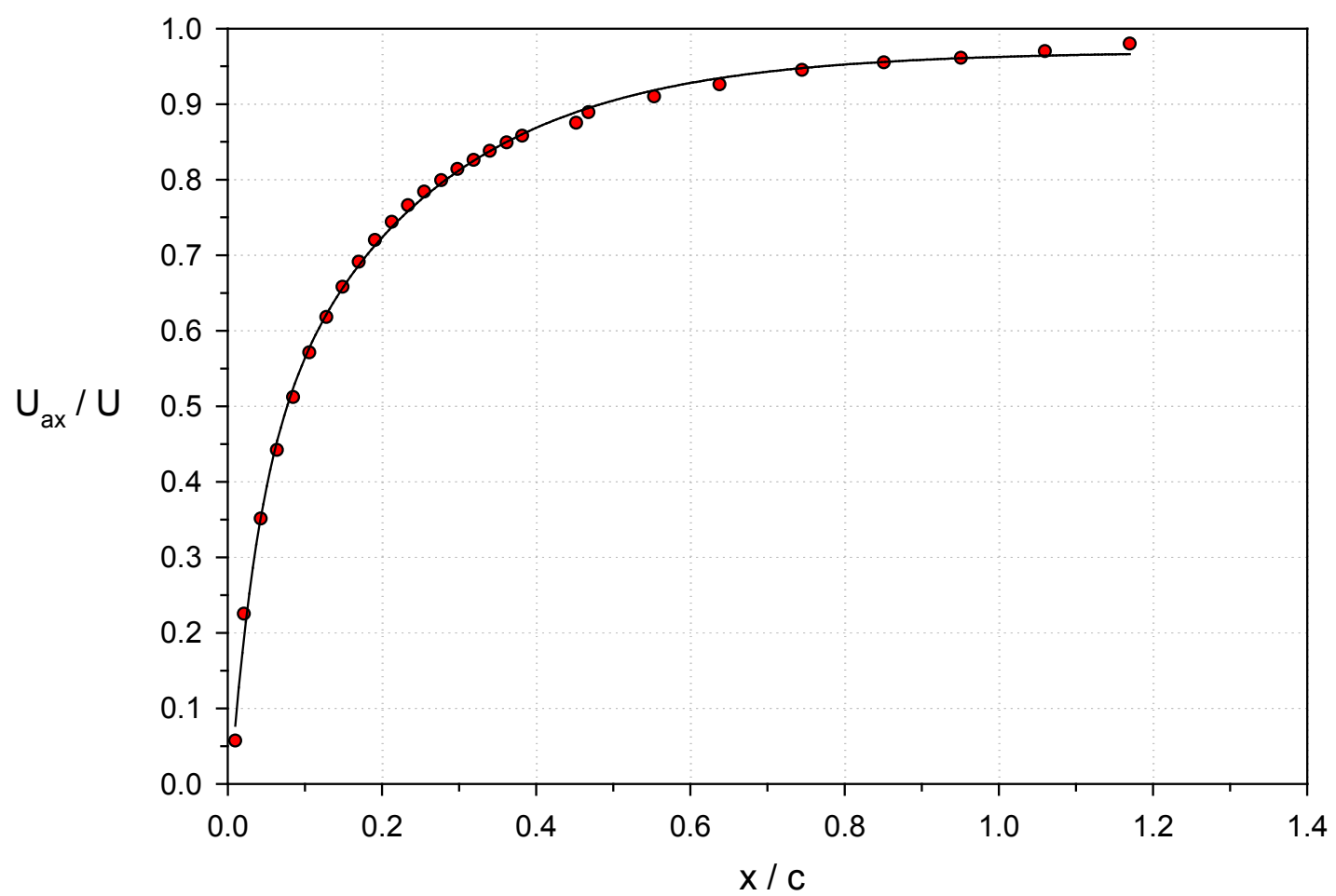

Figure 11.-Wind tunnel measurements of horizontal velocity along stagnation streamline. Velocities taken with LDV along the stagnation streamline for a $0.047 \mathrm{~m}$ chord model (1/10 scale of DBKUP 002) (model reference). 


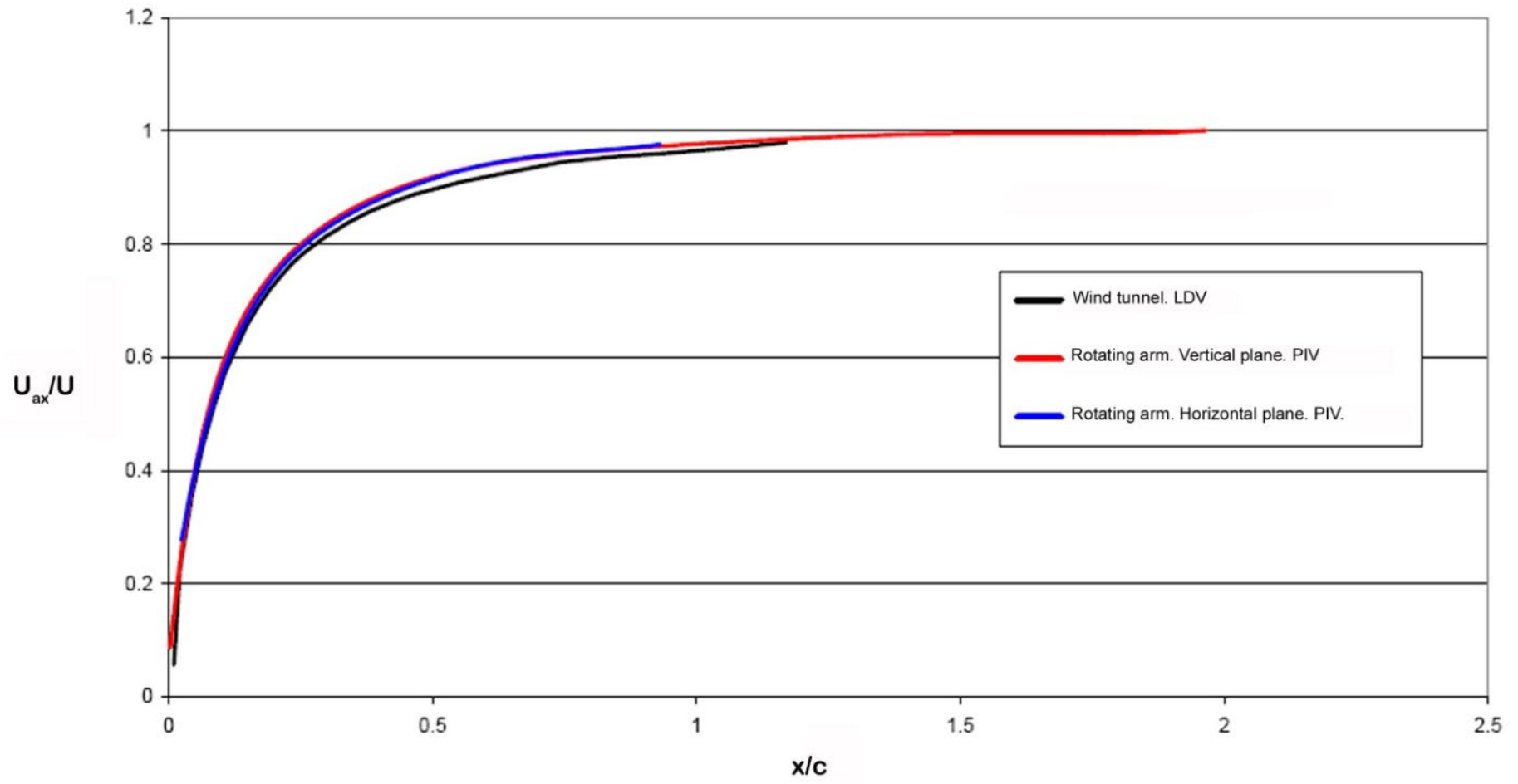

Figure 12.-Comparison of rotating rig PIV measurements with wind tunnel LDV measurements. Non-dimensional velocity comparisons along stagnation streamline (model reference).

\subsection{Droplet Deformation and Breakup}

Some results are presented for cases of droplets in the deformation and breakup stages as they approach the leading edge of an airfoil. The cases are from experiments conducted with the rotating rig.

\subsubsection{Droplet Deformation}

The case considered is one in which droplets are released from a mono-dispersed droplet generator falling vertically through the path of a model moving at a speed that is at least an order of magnitude larger than the droplet vertical velocities. Droplets being generated in these conditions may show oscillations as they fall before entering the model upstream region of influence but at all times remain within bounds and far of any secondary breakup instability that could have been produced by the monosize droplet generator. The vertical velocities may be interpreted as if the droplets approach the airfoil with a small incidence, that is something qualitatively similar to what happens when droplets are encountered in free flight. As the droplets begin to sense the airfoil influence, their shape begins to distort as the water/air surface tension and water viscosity maintain balance with the external air forces. The degree of distortion is dependent on the water properties, the drop size, the drop velocity and the drop acceleration that is in turn defined by the velocity field generated by the airfoil shape, size and velocity. The resulting distortions are due to the complex combination of the mentioned variables at each point of the flow field. They proceed by flattening the side of the droplet facing the airfoil and by elongation in the vertical direction (Figure 13). Depending on droplet conditions, they remain in the deformation stage up to impact or proceed to increasing distortion, leading to different breakup types.

To obtain quantitative information on droplet deformation along a trajectory, the use of the Rotating Arm Facility, with the modifications indicated in Section III, is convenient. The use of a high-speed imaging system is essential to accomplish this task. However, to provide an acceptable image resolution in the high-speed system, a compromise has to be reached between frame rate and magnification, so that the magnitudes of the distorted droplets can be determined.

The experiments presented in this sub-section correspond to a small aspect ratio wing with a high thickness/chord ratio cross section as described in Reference 26. The model has a $0.47 \mathrm{~m}$ chord with 40 percent thickness, a nominal velocity of $90 \mathrm{~m} / \mathrm{s}$, and the initial spherical droplet diameter is $490 \mu \mathrm{m}$. The high-speed camera rate used was 75,000 frames per second and the corresponding resolution in the horizontal and vertical directions are respectively 192 by 312 pixels.

Table I and Figure 14 show the results of an experiment that was conducted in the rotating rig facility and was reported in Reference 26. A drop deformation time sequence taken with the high-speed video system was used to characterize the drop deformation in the horizontal $\left(d_{1}\right)$ and vertical directions $\left(d_{2}\right)$. The two magnitudes measured are presented in Table I in 


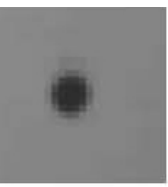

$0 \mu \mathrm{sec}$

Time:

$81.4 \mathrm{~mm}$

$\sim 0$

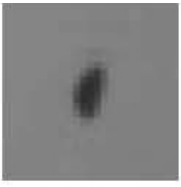

Time:

$346.7 \mu \mathrm{sec}$

Distance:

$-39.6 \mathrm{~mm}$

14.0

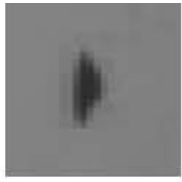

Time:

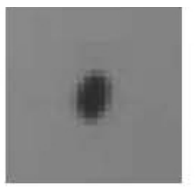

$13.3 \mu \mathrm{sec}$

$-69.6 \mathrm{~mm}$

7.3

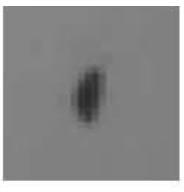

$413.3 \mu \mathrm{sec}$

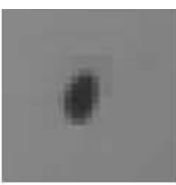

$80.0 \mu \mathrm{sec}$

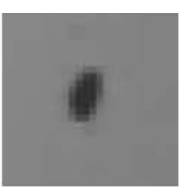

$146.7 \mu \mathrm{sec}$

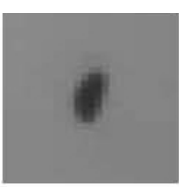

$213.3 \mu \mathrm{sec}$

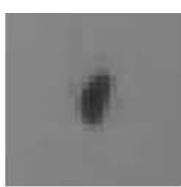

$280.0 \mu \mathrm{sec}$

$-57.6 \mathrm{~mm}$

9.3

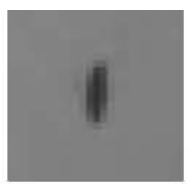

$546.7 \mu \mathrm{sec}$

$-21.6$

23.2

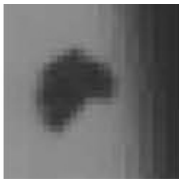

$786.7 \mu \mathrm{sec}$

$0.0 \mathrm{~mm}$

$\begin{array}{lcccc}\text { Distance: } & -7.2 \mathrm{~mm} & -4.8 \mathrm{~mm} & -2.4 \mathrm{~mm} & 0.0 \mathrm{~mm} \\ \text { We: } & 38.2 & 42.0 & 46.2 & 51.0\end{array}$

Figure 13.-Droplet time deformation sequence. Airfoil chord $c=0.47 \mathrm{~m}$. Initial droplet diameter $d=490$ $\mu \mathrm{m}$. Nominal airfoil velocity $U=90 \mathrm{~m} / \mathrm{sec}$. Images from Reference 26.

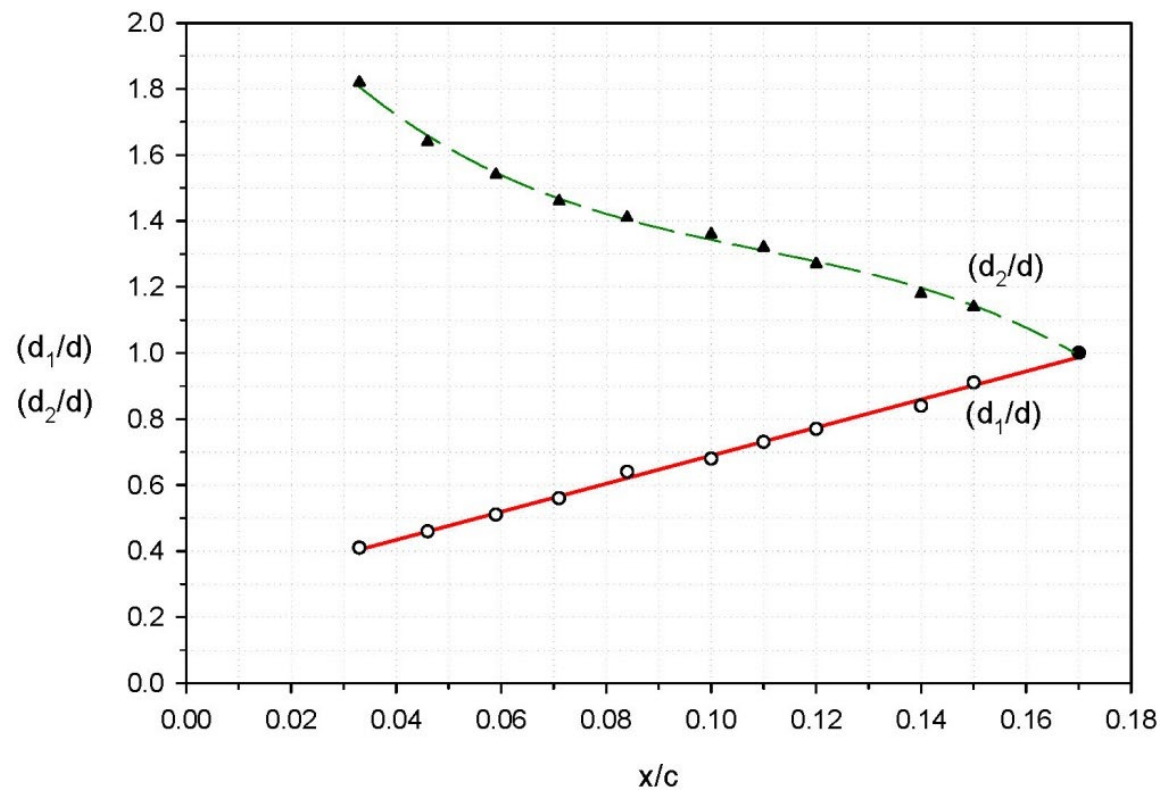

Figure 14.-Droplet deformation dimensions. Airfoil chord $c=0.47 \mathrm{~m}$; initial droplet diameter $d=490 \mu \mathrm{m}$; nominal airfoil velocity $U=90 \mathrm{~m} / \mathrm{sec}$; $d_{1}$ horizontal dimension (minor axis); $d_{2}$ vertical dimension (major axis). 
non-dimensional form against non-dimensional values of time and distance and plotted in Figure 14. Table I also lists the values of the Reynolds, Weber and Bond numbers based on the original droplet diameter.

TABLE I.-DROPLET DEFORMATION ALONG STAGNATION LINE

\begin{tabular}{|c|c|c|c|c|c|c|}
\hline \multicolumn{7}{|c|}{ Airfoil chord $c=0.47 \mathrm{~m}$} \\
\hline \multicolumn{7}{|c|}{ Initial droplet diameter $d=490 \mu \mathrm{m}$} \\
\hline \multicolumn{7}{|c|}{ Nominal airfoil velocity $U=90 \mathrm{~m} / \mathrm{s}$} \\
\hline \multicolumn{7}{|c|}{ Droplet time to reach airfoil $t$} \\
\hline \multicolumn{7}{|c|}{ Droplet distance to airfoil $x$} \\
\hline \multicolumn{7}{|c|}{ Droplet dimension along minor axis $d_{1}$ (horizontal) } \\
\hline \multicolumn{7}{|c|}{ Droplet dimension along major axis $d_{2}$ (vertical) } \\
\hline$t /(d / U)$ & $(x / c)$ & $\mathrm{Re}_{d}$ & $\mathrm{We}_{d}$ & $\mathrm{Bo}_{d}$ & $\left(d_{1} / d\right)$ & $\left(d_{2} / d\right)$ \\
\hline 144.5 & 0.17 & 946 & 6.9 & 11.8 & 1.00 & 1.00 \\
\hline 142.2 & 0.15 & 1013 & 7.3 & 12.0 & 0.91 & 1.14 \\
\hline 130.0 & 0.14 & 1081 & 8.2 & 13.0 & 0.84 & 1.18 \\
\hline 117.6 & 0.12 & 1149 & 9.3 & 14.0 & 0.77 & 1.27 \\
\hline 105.4 & 0.11 & 1217 & 10.6 & 15.4 & 0.73 & 1.32 \\
\hline 93.1 & 0.10 & 1284 & 12.1 & 17.1 & 0.68 & 1.36 \\
\hline 80.8 & 0.08 & 1419 & 14.0 & 20.6 & 0.64 & 1.41 \\
\hline 68.7 & 0.07 & 1588 & 16.4 & 27.4 & 0.56 & 1.46 \\
\hline 56.4 & 0.06 & 1690 & 19.3 & 37.7 & 0.51 & 1.54 \\
\hline 44.1 & 0.05 & 1825 & 23.2 & 51.5 & 0.46 & 1.64 \\
\hline 31.9 & 0.03 & 2027 & 28.2 & 75.4 & 0.41 & 1.82 \\
\hline
\end{tabular}

\subsubsection{Droplet Breakup}

The final stage of a drop deformation as it approaches the airfoil surface is one in which the drop rate of distortion with time is an order of magnitude larger than in the initial deformation stage.

This implies that the liquid inside is displaced, accumulating in a very short time at specific locations, creating conditions leading to instability and finally to breakup (Figure 15). One of the critical questions in relation to the instability onset is the disintegration into a fine spray of secondary droplets. This disintegration is very important because of the potential effect it has on the impinging collection efficiency over the surface and presents a serious challenge to the experiments.

To follow the droplet breakup process, a high-speed video system is an essential component. However, for the final outcome, including the details of the disintegration process, resolution to characterize all the problem variables. An alternative such as a high resolution single image system is needed to complement the high-speed video. For the operation conditions of the facility, the breakup takes place at locations that are near enough to the model surface so that both the surface and droplet can be included within the image field of view. The experimental conditions used to obtain the breakup results that are presented below are: model velocity of $90 \mathrm{~m} / \mathrm{s}$, chord of $0.47 \mathrm{~m}$ and thickness of 40 percent with droplets of $414 \mu \mathrm{m}$.

Measurements of the minimum and maximum droplet cross section dimensions are taken to characterize the final stage leading to breakup as they change along the stagnation line trajectory, as was presented in Reference 26. The two magnitudes are presented in non-dimensional form with the non-dimensional time and distances to reach the airfoil in Table II and plotted in Figure 16. A sequence of the last stage of the breakup showing disintegration is presented in Figure 17. The sequence is for different droplets of the same diameter. The diameter of the droplets is $250 \mu \mathrm{m}$. The velocity of the model is $90 \mathrm{~m} / \mathrm{s}$. The model chord is $0.47 \mathrm{~m}$ with a thickness of 40 percent.

\begin{tabular}{|c|c|c|c|}
\hline \multicolumn{4}{|c|}{$\begin{array}{l}\text { TABLE II.-DROPLET BREAKUF } \\
\text { ALONG STAGNATION LINE }\end{array}$} \\
\hline \multirow{7}{*}{\multicolumn{4}{|c|}{$\begin{array}{l}\text { Airfoil chord } c=0.47 \mathrm{~m} \\
\text { Initial droplet diameter } d=414 \mu \mathrm{m} \\
\text { Nominal airfoil velocity } U=90 \mathrm{~m} / \mathrm{s} \\
\text { Droplet time to reach airfoil } t \\
\text { Droplet distance to airfoil } x \\
\text { Minimum length } d_{1} \\
\text { Maximum length } d_{2}\end{array}$}} \\
\hline & & & \\
\hline & & & \\
\hline & & & \\
\hline & & & \\
\hline & & & \\
\hline & & & \\
\hline$t /(d / U)$ & $(x / c)$ & $\left(d_{1} / d\right)$ & $\left(d_{2} / d\right)$ \\
\hline 31.6 & 0.033 & 0.47 & 1.95 \\
\hline 21.1 & 0.022 & 0.77 & 2.25 \\
\hline 15.8 & 0.016 & 0.88 & 2.08 \\
\hline 10.7 & 0.011 & 1.24 & 2.19 \\
\hline 5.3 & 0.005 & 1.60 & 2.14 \\
\hline
\end{tabular}

\subsection{Droplet Impact}

Results of two cases of large droplets impacting a surface covered by a thin water film are presented. These are: low incidence impact and perpendicular impact. 


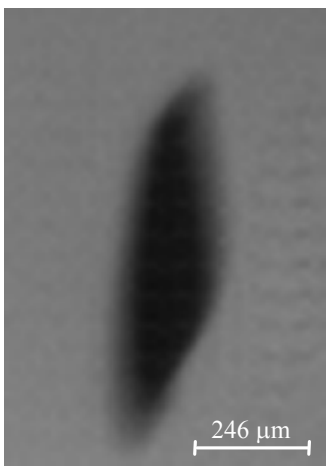

$t=0 \mu \mathrm{sec}$

$15.5 \mathrm{~mm}$

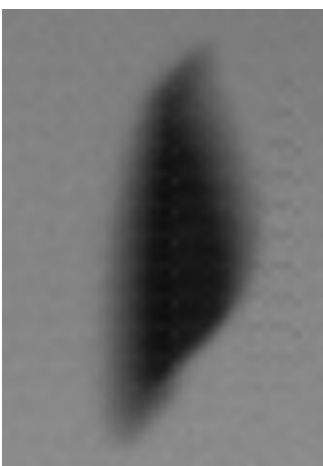

$t=57.1 \mu \mathrm{sec}$

$10.3 \mathrm{~mm}$

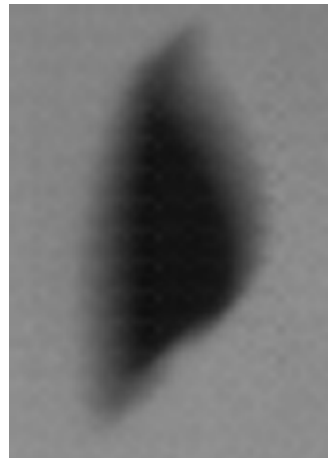

$t=85.7 \mu \mathrm{sec}$

$7.7 \mathrm{~mm}$

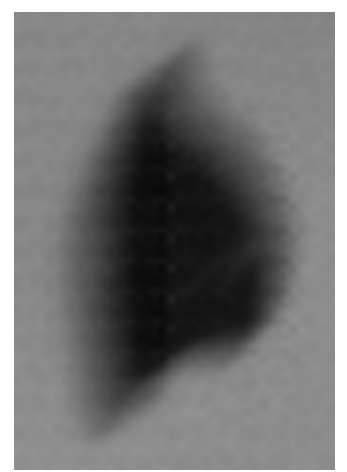

$t=114.3 \mu \mathrm{sec}$

$5.2 \mathrm{~mm}$

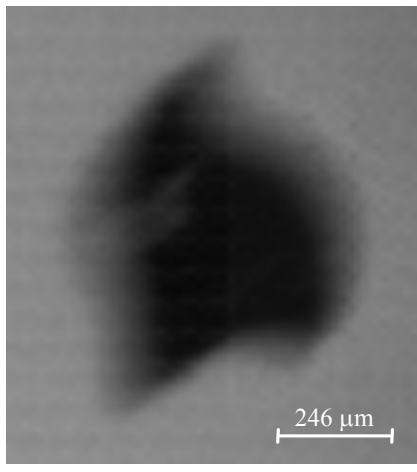

$t=142.9 \mu \mathrm{sec}$

$2.6 \mathrm{~mm}$

Figure 15.-Droplet time deformation sequence. Airfoil chord $c=0.47 \mathrm{~m}$; initial droplet diameter $d=490 \mu \mathrm{m}$; nominal airfoil velocity $U=90 \mathrm{~m} / \mathrm{sec}$. Images from Reference 26 .

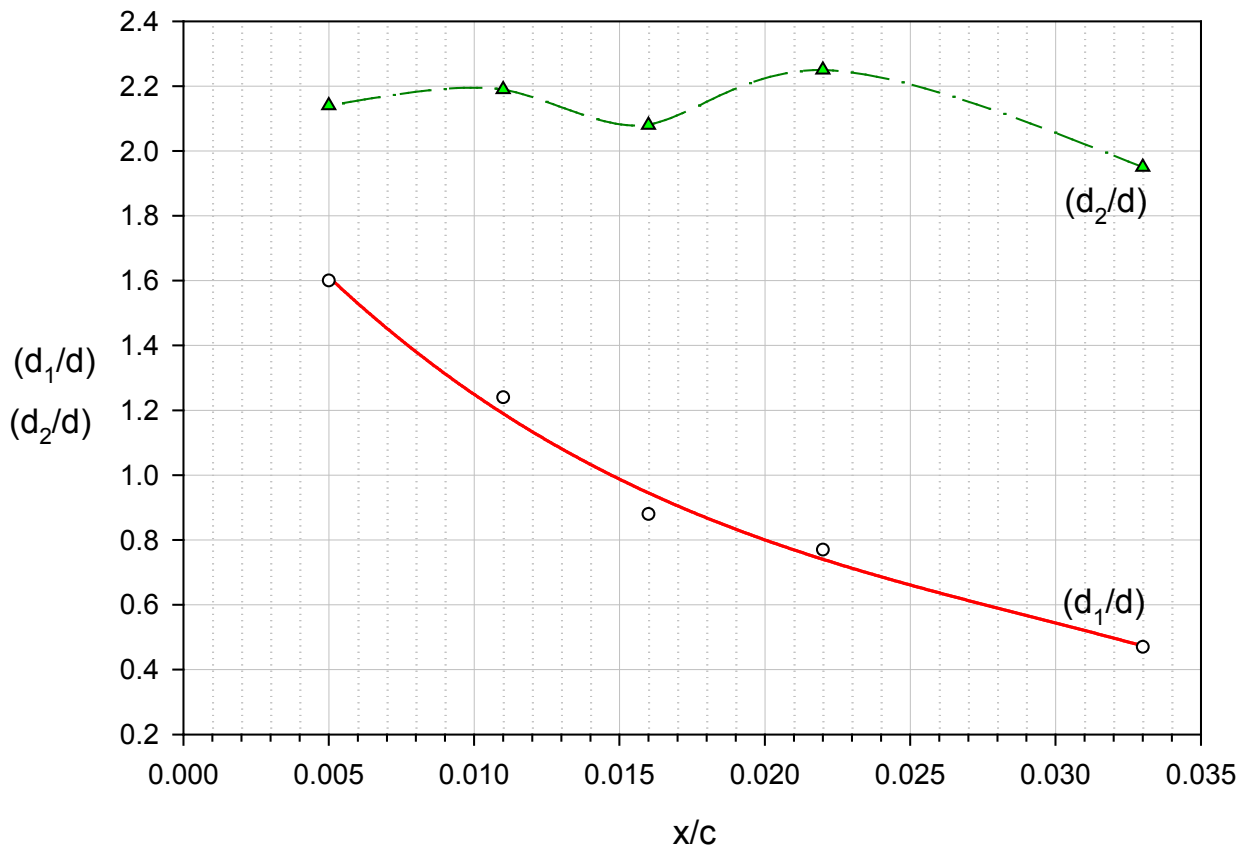

Figure 16.-Droplet breakup dimensions. Airfoil chord $c=0.47 \mathrm{~m}$; initial droplet diameter $d=414 \mu \mathrm{m}$; nominal airfoil velocity $U=90 \mathrm{~m} / \mathrm{sec} ; d_{1}$ horizontal axis; $d_{2}$ vertical axis. 


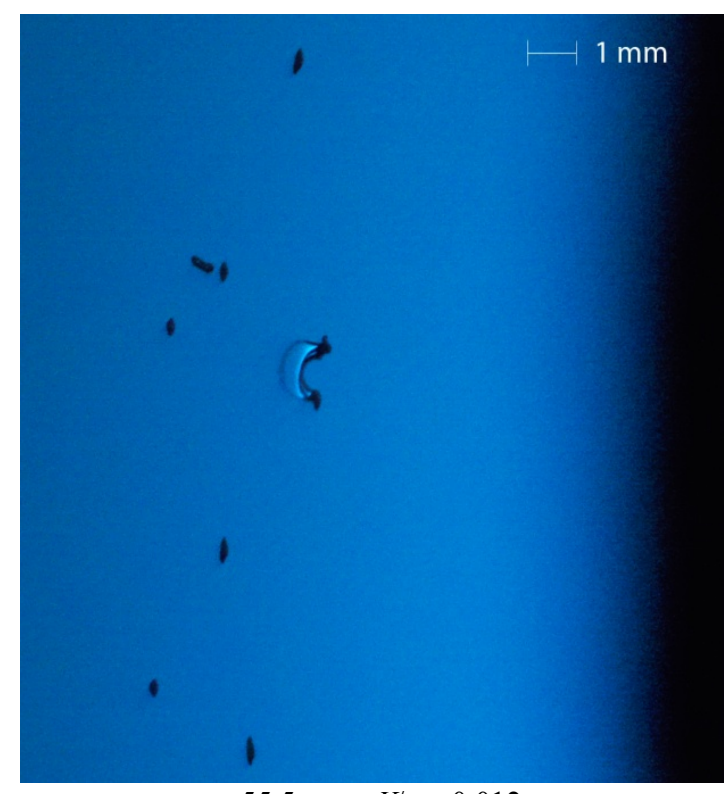

$t=55.5 \mu \mathrm{sec}, X / c=0.012$

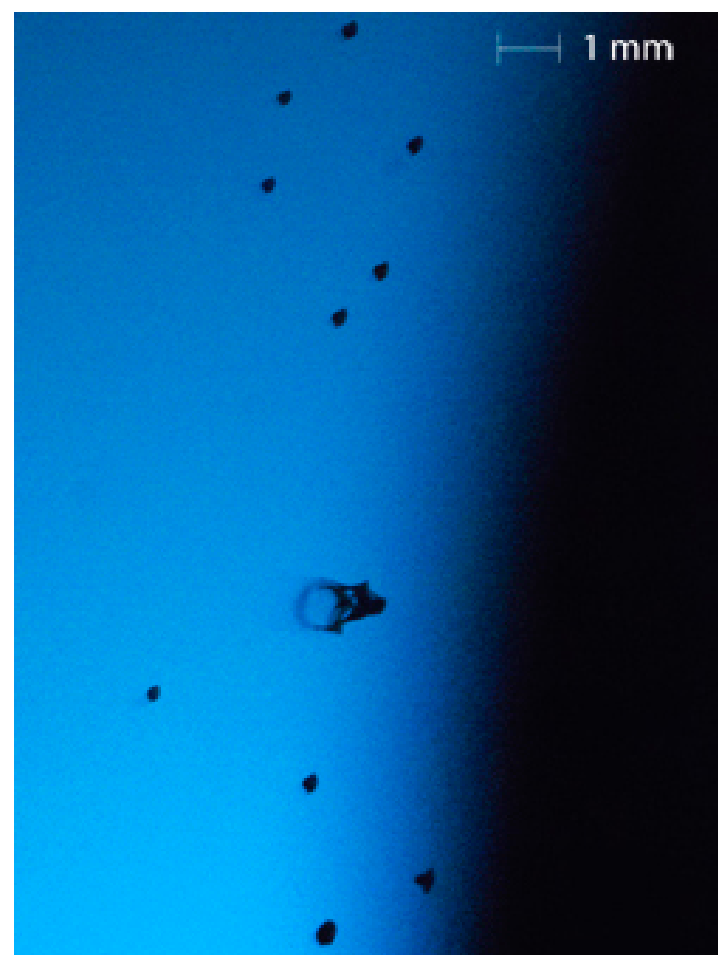

$t=11.1 \mu \mathrm{sec}, X / c=0.002$

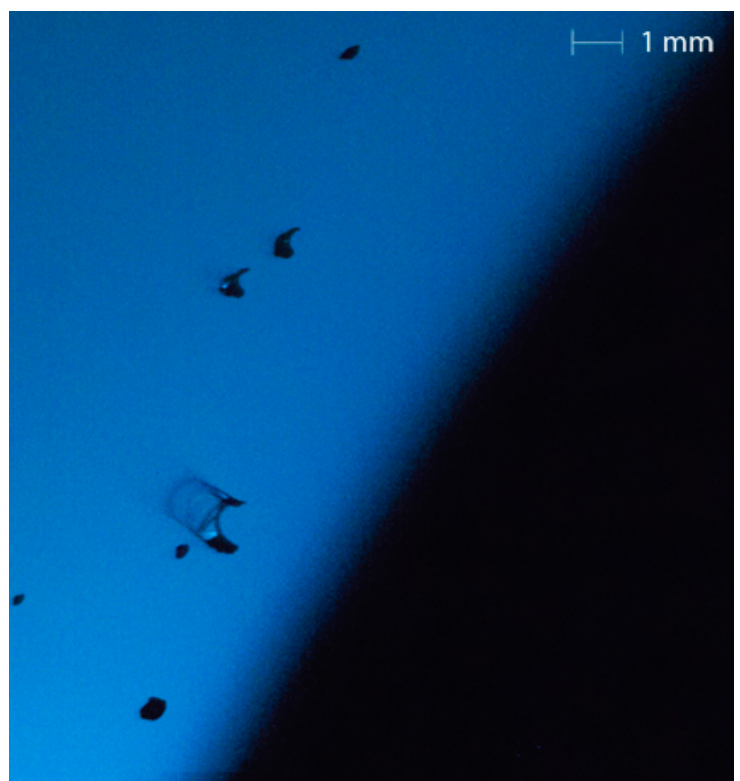

$t=31.1 \mu \mathrm{sec}, X / c=0.006$

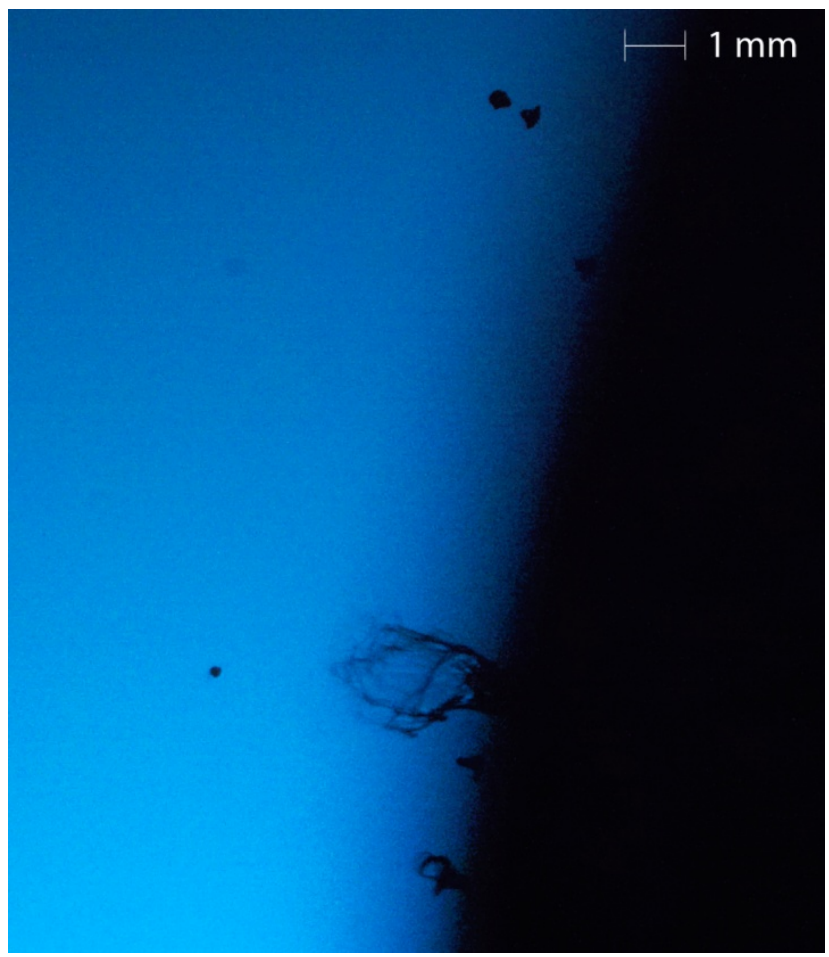

$t=0 \mu \mathrm{sec}, X / c=0$

Figure 17.-Droplet Breakup. Last Stage. $c=0.47 \mathrm{~m} ; U=90 \mathrm{~m} / \mathrm{sec}$. Time sequence of high resolution images of (physically different) droplets of same diameter $(250 \mu \mathrm{m})$. Each droplet is very near the airfoil surface (dark shadow on the right side). 


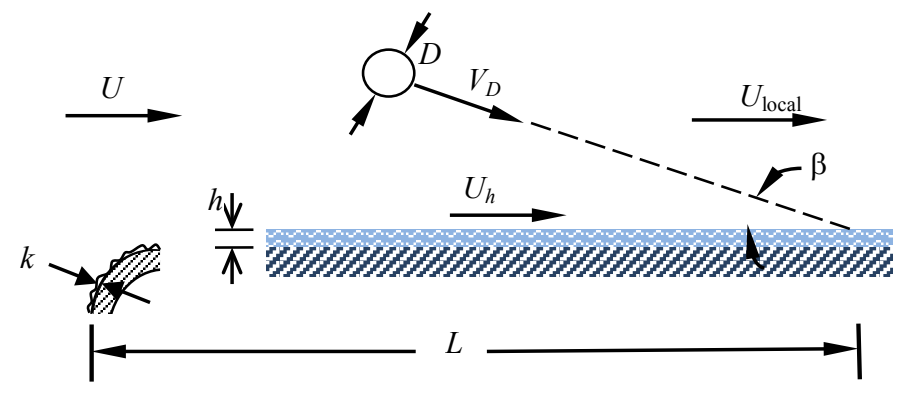

Figure 18.-Single Angular Drop Impact. Incidence variables are: $U$ incoming air velocity; $D$ droplet diameter; $V_{d}$ droplet velocity; $U_{\text {local }}$ local air velocity; $k$ surface roughness; $h$ water film thickness; $U_{h}$ water film velocity; $L$ distance from impact to leading edge; $\beta$ droplet incidence angle.

\subsubsection{Low Incidence Impact}

Spherical droplets with incidences such that the resultant droplets being ejected extend only over part of the windward side of the circumference on the surface where the impact is taking place (approximately below $12^{\circ}$ ) are considered to be low incidence (Figure 18) and the splash schematically looks as indicated in Figure 19. As time increases in the impact process, the droplet merges at the same rate as the normal impact velocity with respect to the surface, forming a thin water membrane with filaments from which the droplets are ejected. The downstream side merges smoothly with the liquid film underneath, without ejection of droplets. When the droplet flattens completely, a crater still persists and the remaining pressure difference at the crater base continues forcing ejection on the upstream side and mixing droplet liquid with the high velocity moving liquid film underneath, at the same time that a liquid film wake-like shape extends to large distances downstream. Crater disappearance indicates pressure equalization with the surrounding liquid and no more tendency to either form a larger crown or mix with the liquid film. Through the action of water viscosity, the wake-like liquid deposited shape will tend to extend downstream and the crown wall to detach from the splash-deposited wake. This thin water wall breaks into filaments which in turn disintegrate into droplets exchanging momentum and energy with the external air flow. No relative velocity air-liquid particles indicates the end of the splashing process.

The process is shown in the time sequence images of Figure 20. In order to obtain sufficient resolution, these images do not correspond to the same droplet, but to different generated droplets of the same size, captured with shortduration $(3 \mu \mathrm{sec})$ high intensity lamps and controlled time delays. The length of arm radius used was $1.25 \mathrm{~m}$; the model was a flat plate with a length of $200 \mathrm{~mm}$, width of $100 \mathrm{~mm}$ and a thickness of $1 \mathrm{~mm}$, with a rounded leading edge. The linear velocity at the plate centerline was $60 \mathrm{~m} / \mathrm{s}$ and spherical droplets with diameters of $4 \mathrm{~mm}$ falling at $4 \mathrm{~m} / \mathrm{s}$ on a line at most $60 \mathrm{~mm}$ from the leading edge. The water film thickness was not measured in this experiment but it could be estimated,

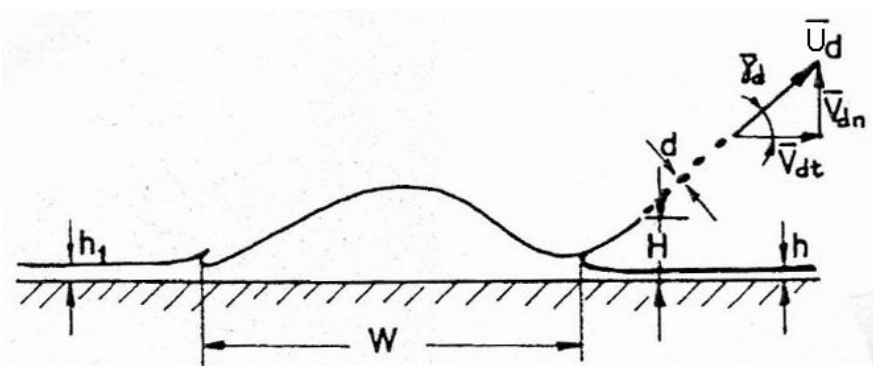

Figure 19.-Low incidence splash relative to a fixed observer (drop coalescence stage). Model reference axis. $W$ crater width; $h_{1}$ water film thickness upstream of splash, $h$ water film thickness downstream of splash, $H$ crown wall height, $d$ mean ejected droplets diameters, $\overline{\boldsymbol{U}}_{\boldsymbol{d}}$ is the average magnitude of droplet velocities.

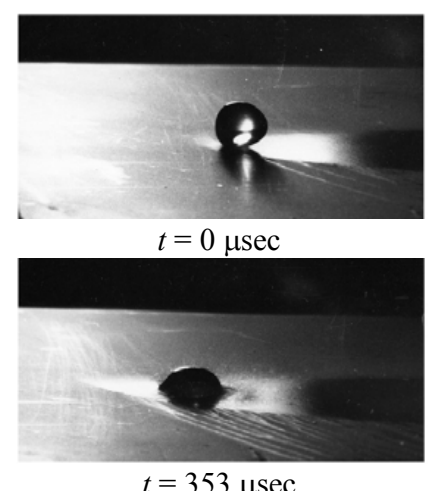

$t=353 \mu \mathrm{sec}$

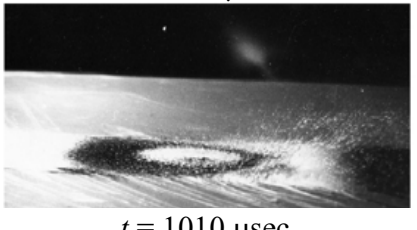

$t=1010 \mu \mathrm{sec}$

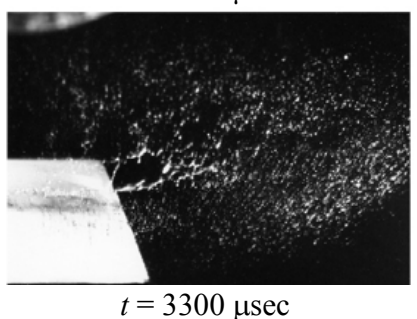

Figure 20.-Low incidence splash (external observer's reference) $\beta=4^{\circ}, D=4 \mathrm{~mm}, V_{D}=60 \mathrm{~m} / \mathrm{s}$. The figure is a time sequence for physically different droplets of the same diameter.

assuming one impact per revolution based on the generated droplet distances, at $10 \mathrm{~mm}$ in width (measured from the images). Adding water loss through splashing or centrifugal effects leads to a value for the film thickness of about $15 \mu \mathrm{m}$, which yields a film-thickness to droplet-diameter ratio in the order of $3.75 / 1000$. The assumption for water film thickness is made based on previous measuring experience, performed to understand the deposited water film behavior after rotating the model in a condition similar to the one under consideration, 
where it was observed that when droplets were released at one location, the water film had a sudden increase in thickness due to the droplet impact, followed by a progressive decrease along the circumferential trajectory to reach values near the minimum that can be detected.

Average measurements of ejected droplet velocity components and ejection angles may be made by measuring distances in each of the images from the average ejected droplets front location, to the point on the surface where contact is made at the initial time for the first signs of ejection. Measurements of time $t$, distances $x$ and $y$ define the average horizontal $u_{d t}$ and vertical $u_{d n}$ velocities and ejected angle for each of the images. The magnitudes are with respect to an external observer axis and are presented in Table III. The values of this table when converted to the model reference axis are shown in Table IV and plotted in Figure 21 and Figure 22. The set of images have sufficient resolution to measure droplet size and, if appropriate image analysis software is used, a complete droplet spectrum at different stages of the process can be obtained. Direct inspection measurements indicate, from the spray of Figure 20 (last image), a range of diameters from 10 to $100 \mu \mathrm{m}$.
TABLE III.-EJECTED DROPLET MEASUREMENTS (EXTERNAL REFERENCE)

\begin{tabular}{|c|c|c|c|c|c|}
\hline \multicolumn{5}{|c|}{ Incident conditions $U_{d}=60 \mathrm{~m} / \mathrm{s} ; d=4 \mathrm{~mm}, \beta=4^{\circ}$} \\
\hline $\begin{array}{c}t, \\
\mu \mathrm{s}\end{array}$ & $\begin{array}{c}x, \\
\mathrm{~mm}\end{array}$ & $\begin{array}{c}y, \\
\mathrm{~mm}\end{array}$ & $\begin{array}{c}u_{d t}, \\
\mathrm{~m} / \mathrm{s}\end{array}$ & $\begin{array}{c}u_{d n}, \\
\mathrm{~m} / \mathrm{s}\end{array}$ & $\begin{array}{c}\gamma_{\mathrm{d}}, \\
\circ\end{array}$ \\
\hline 180 & 3.2 & 1.8 & 17.8 & 10 & 30 \\
353 & 5.6 & 1.9 & 15.8 & 5.1 & 18 \\
705 & 9.0 & 2.4 & 12.8 & 3.4 & 15 \\
1100 & 14.0 & 3.2 & 12.7 & 2.9 & 12 \\
1350 & 15.8 & 3.4 & 11.7 & 2.5 & 11 \\
\hline
\end{tabular}

TABLE IV.-RESULTS (MODEL REFERENCE)

\begin{tabular}{|c|c|c|}
\hline \multicolumn{2}{|c|}{ Incident conditions $U_{d}=60 \mathrm{~m} / \mathrm{s} ; d=4 \mathrm{~mm}, \beta=4^{\circ}$} \\
\hline$t /\left(D / V_{D n}\right)$ & $u_{d} / V_{D}$ & $\begin{array}{c}\gamma_{d}, \\
\circ\end{array}$ \\
\hline 0.18 & 1.31 & 7 \\
0.353 & 1.26 & 4 \\
0.705 & 1.22 & 3 \\
1.1 & 1.21 & 2 \\
1.35 & 1.2 & 2 \\
\hline
\end{tabular}

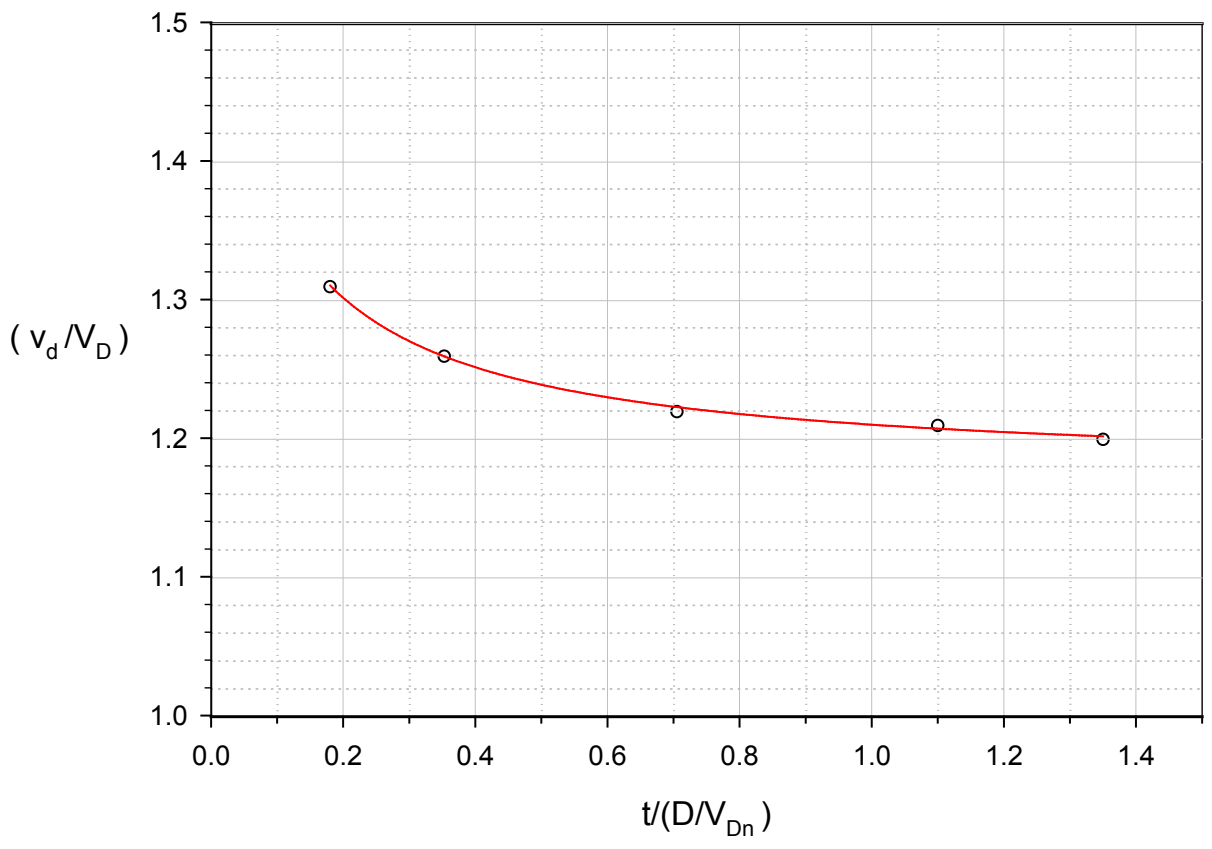

Figure 21.-Low incidence averaged ejected droplets velocities relative to model $V_{d}=60 \mathrm{~m} / \mathrm{s}, d=4 \mathrm{~mm}, \beta=4$. Impacting on a water film thickness of the order of $10 \mu \mathrm{m}$. Obtained from a time sequence of single images of (physically different) droplets. 


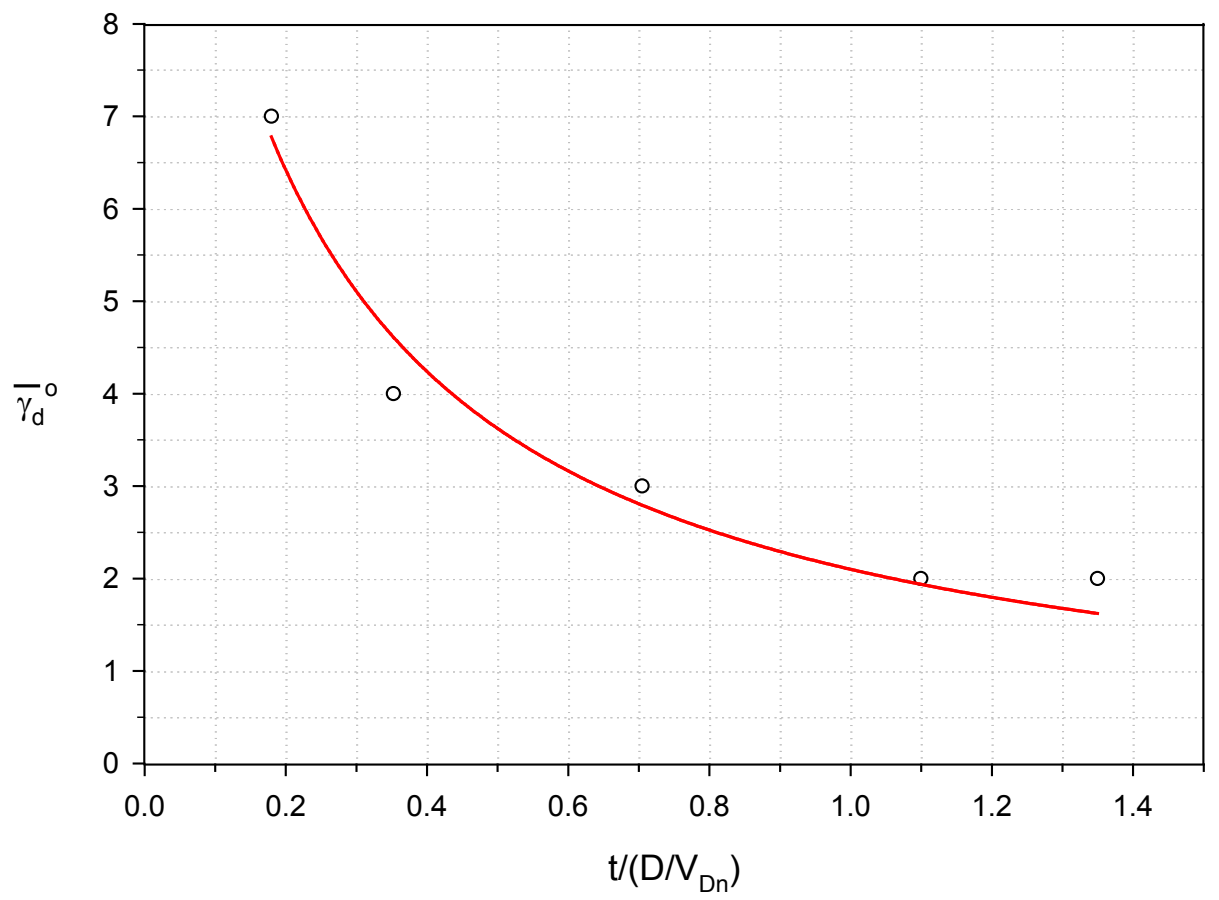

Figure 22.-Low incidence averaged ejected droplets angles relative to model.

$V_{d}=60 \mathrm{~m} / \mathrm{s}, d=4 \mathrm{~mm}, \beta=4^{\circ}$. Obtained from a time sequence of single images of (physically different) droplets

\subsubsection{Perpendicular Impact}

Spherical droplets impacting normal to the surface result in an axially symmetric splash configuration with respect to a perpendicular axis to the surface that contains the initial contact point droplet-surface. The physical process starts with the contact at high speed of the water with the surface, with some deformation of the sphere without any droplets being ejected, this being an indication of compressibility effects being generated inside the droplet during a few microseconds. These high pressures are responsible for the initial high velocity droplets directed radially outwards ("jetting"), that are partially converted into trajectories with normal components at the edge of the crater base. They form a very short continuous crater wall, with water being discharged through it, leading to the formation of very thin filaments that breakup into a very small diameter droplet mist. The crater base grows rapidly to an appreciable size while the crater walls remain short and near the surface (Figure 23).

As described in previous sections, in order to obtain the best possible resolution for the images, a time sequence with different droplets of the same diameter are captured in the shadowgraph/lateral mode (Figure 24). A $3 \mu \mathrm{sec}$ lamp triggered through synchronization and time delay was used for model and droplet positions when their electronic pulses coincide within a predefined time window. The arm had a 1.25 $\mathrm{m}$ radius and the stagnation point model had a circular flat surface on which the droplets were made to impact (Figure 25). The circle diameter was $80 \mathrm{~mm}$ and the model linear velocity was $60 \mathrm{~m} / \mathrm{s}$ with droplets of $4 \mathrm{~mm}$. The water film thickness on the impact surface was estimated, based on the approximation of one impact per revolution extending over three quarters of the circular surface (from observations). It yields a film thickness of the order of $10 \mu \mathrm{m}$, an estimate obtained following the same criterion as for the low incidence impacts discussed in the previous section (Ref. 32).

Measurements of the perpendicular impact that characterizes the splash are made directly from the time sequence images for its geometrical variables and the average values of the ejected droplet velocity magnitudes and direction. The variables measured are the crater diameter, the horizontal extension of the crown/filaments length and the corresponding height from the surface, the average ejected droplet velocity magnitude and the average ejected droplet angle with respect to the surface. They are measured from images (Ref. 33) taken simultaneously from lateral Shadowgraphs and frontal views (Figure 26). 


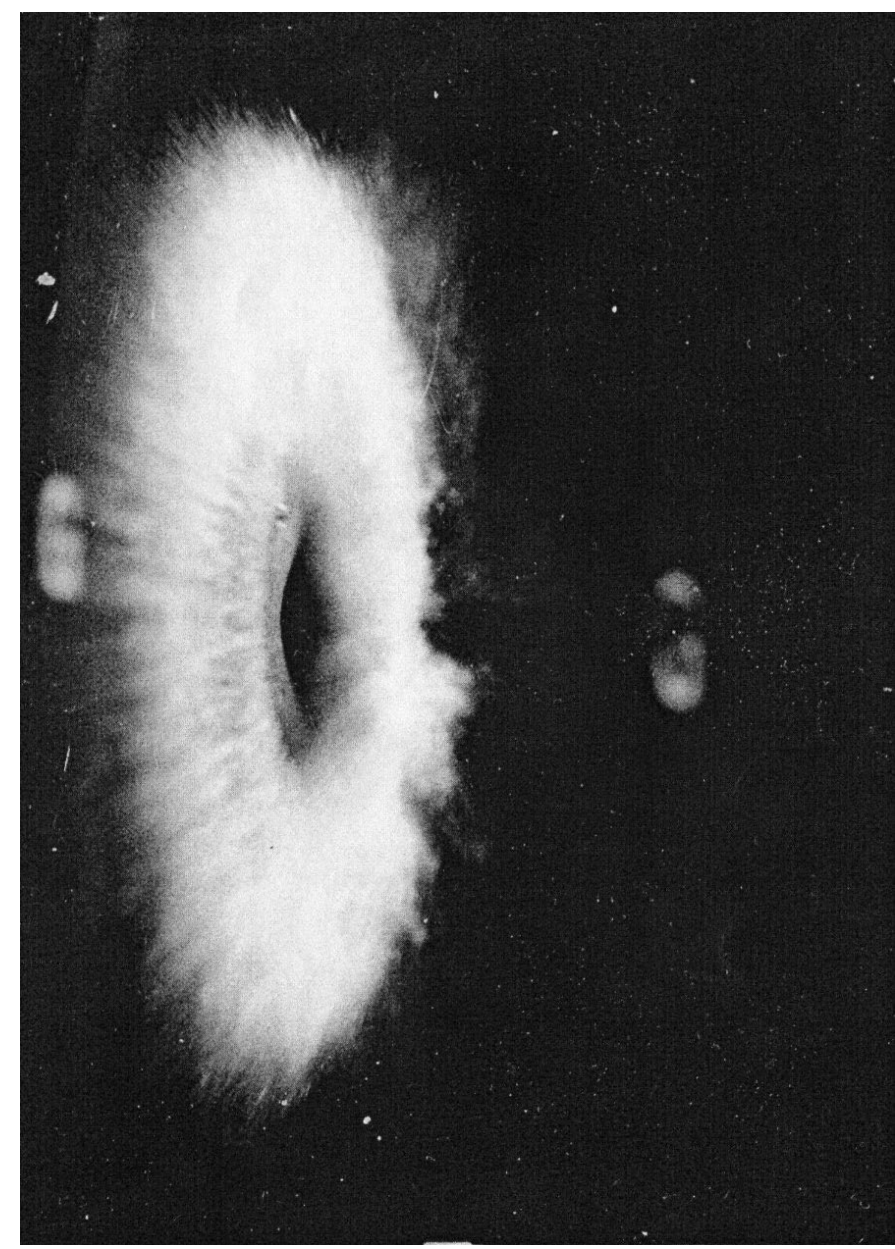

Figure 23.-Initial stage of a perpendicular spherical droplet splash. Impact velocity $60 \mathrm{~m} / \mathrm{s}$; droplet diameter $4 \mathrm{~mm}$; water film thickness $\sim 10 \mu \mathrm{m}$

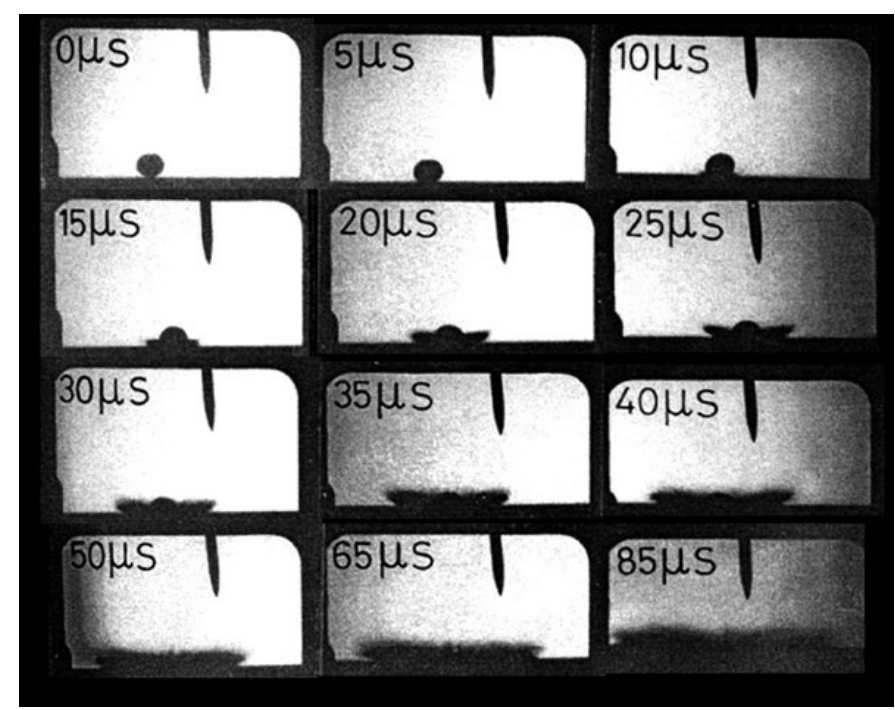

Figure 24.-Time sequence shadow graphs of spherical droplet impact. Impact velocity $60 \mathrm{~m} / \mathrm{s}$; droplet diameter $4 \mathrm{~mm}$; water film thickness $\sim 10 \mu \mathrm{m}$.

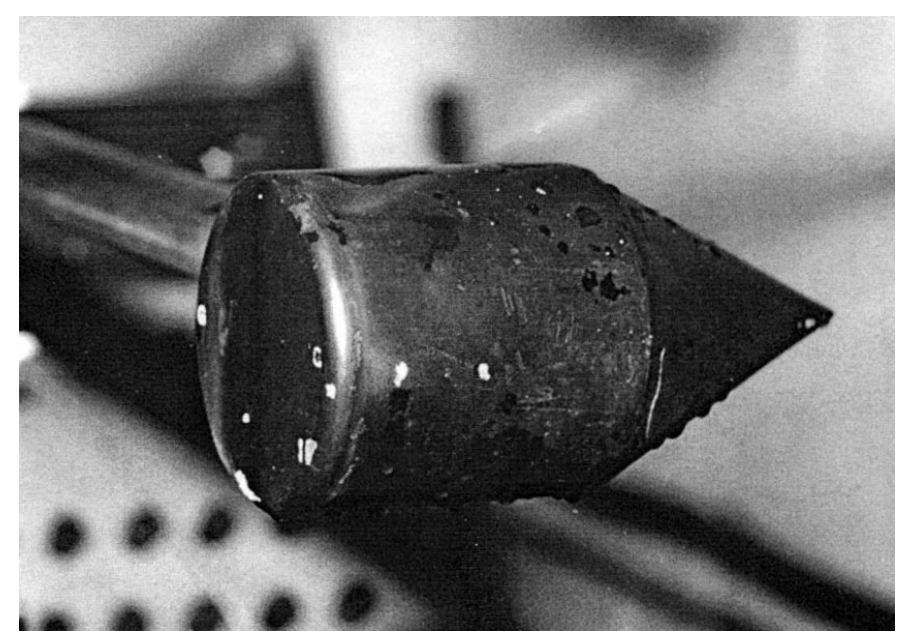

Figure 25.-Model attached to the rotating arm 


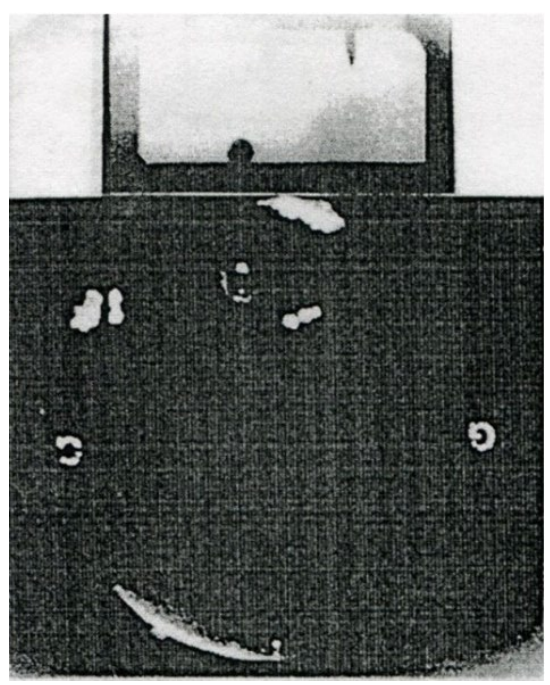

$t \approx 10 \mu \mathrm{sec}$

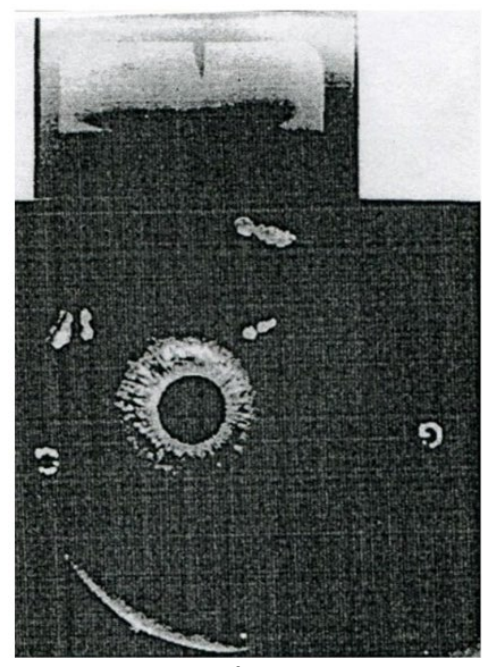

$t \approx 70 \mu \mathrm{sec}$

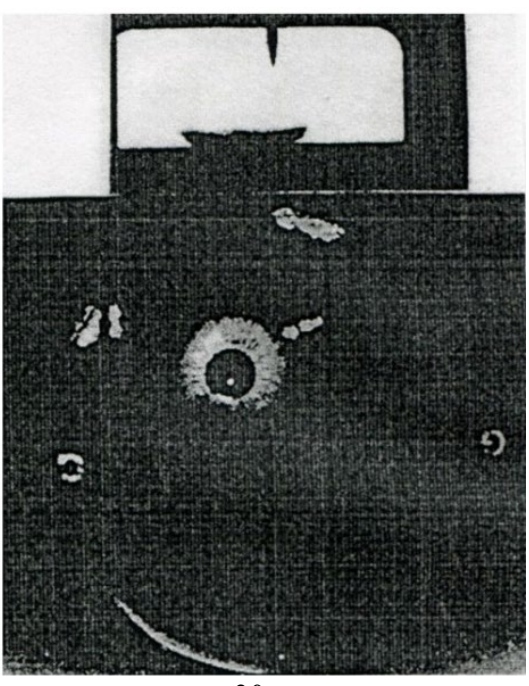

$t \approx 30 \mu \mathrm{sec}$

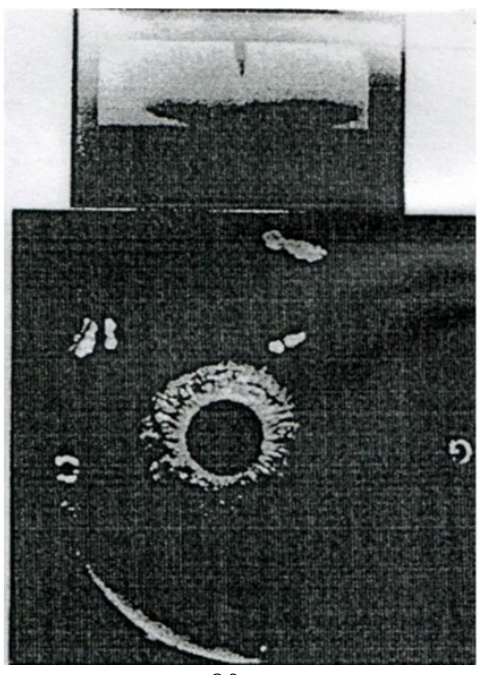

$t \approx 80 \mu \mathrm{sec}$

Figure 26.-Simultaneous shadowgraphs and frontal images, impact velocity $60 \mathrm{~m} / \mathrm{sec}$, droplet diameter $4 \mathrm{~mm}$, water film thickness $\sim 10 \mu \mathrm{m}$.

These values are measured with respect to an external observer frame of reference and shown in non-dimensional form in Table V and Figure 27, Figure 28, and Figure 29. The diameters of the ejected droplets cannot be obtained from the presented images since the ejecta appear as a compact cloud, where individual droplets cannot be identified in the initial phases of the process. For images corresponding to the last part of the process, the resolution is poor. The combination of these two difficulties indicates that challenges associated with this case could be so important as to make the measurements through this technique unfeasible. Also, due to the proximity of the ejecta to the surface, the use of laser instrumentation such as PIV or PDPA could also be a challenge. In order to estimate an order of magnitude for average diameters of ejecta that are being generated during certain amount of time, the following assumptions are made: 1) spherical shape, 2) the droplet inertial forces are entirely balanced by aerodynamic forces (drag), 3) no interaction between them so that the droplet Drag Coefficient may be taken as if the droplets were completely isolated. Average droplet velocities and accelerations are calculated from the images during the time span in terms of non-dimensional times based on the characteristic impact time $d / U_{d}$. For values of this parameter between 0 and 1 , the average diameter is about $5 \mu \mathrm{m}$; for values between 1 and 2 , the average results are of about $15 \mu \mathrm{m}$ and finally, for values between 2 and 3 the average value is of the order of $20 \mu \mathrm{m}$. Recall that these average values correspond to an incident droplet of $4 \mathrm{~mm}$ diameter with $60 \mathrm{~m} / \mathrm{s}$, impacting on a water film thickness of the order of $10 \mu \mathrm{m}$. 
TABLE V.-PERPENDICULAR IMPACT

SPLASH CHARACTERISTICS

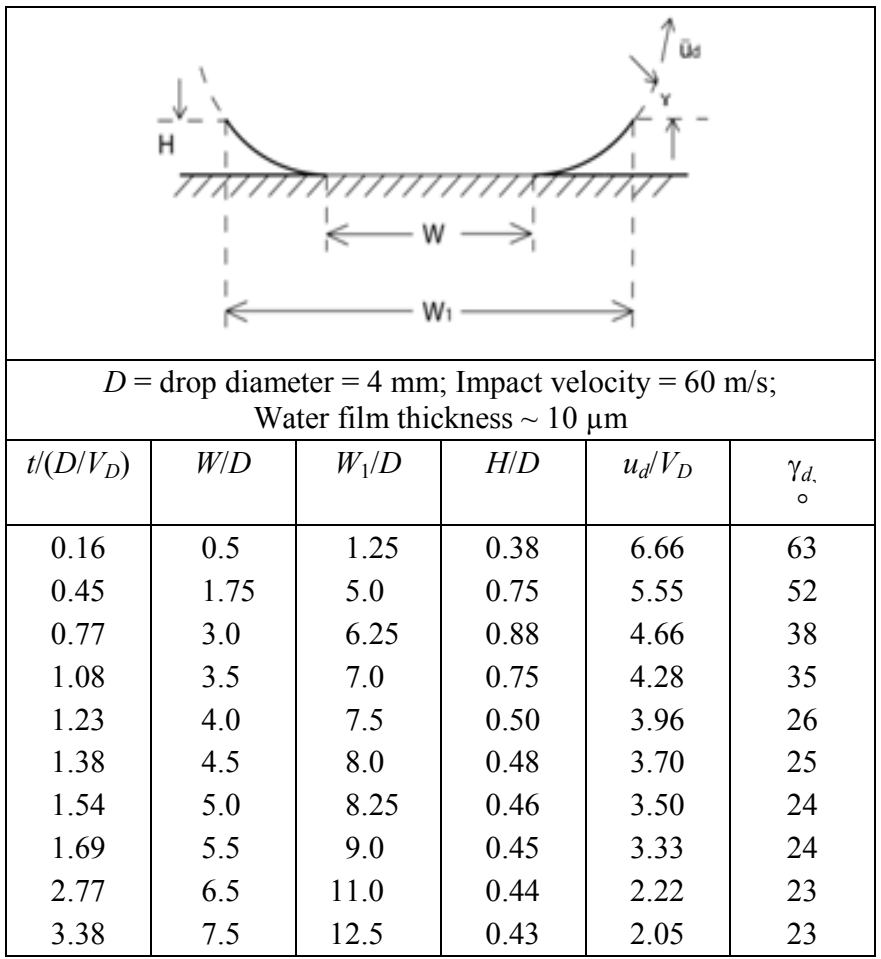

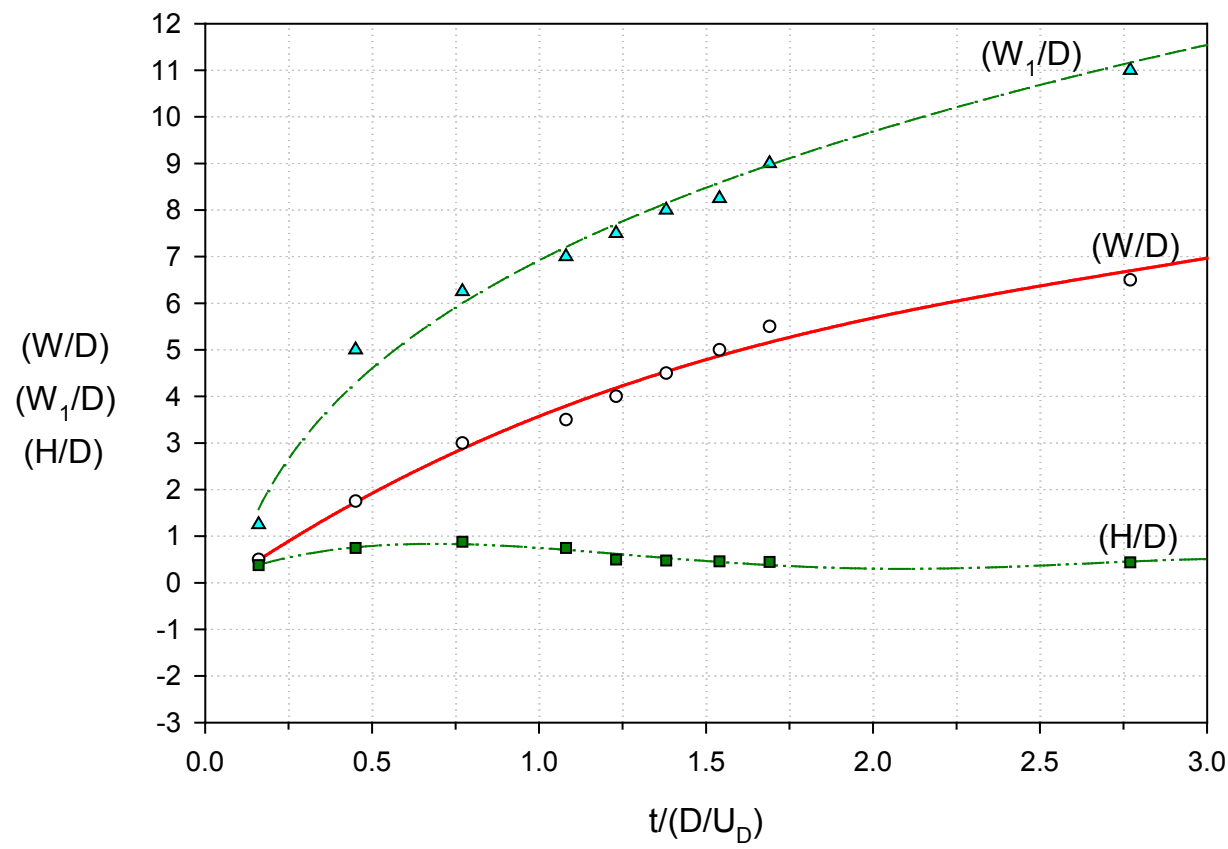

Figure 27. - Time evolution of crater dimensions. Droplet incident velocity $U_{i}=60 \mathrm{~m} / \mathrm{s}$, droplet diameter $d=4 \mathrm{~mm}$, water film thickness $\sim 10 \mu \mathrm{m}$ 


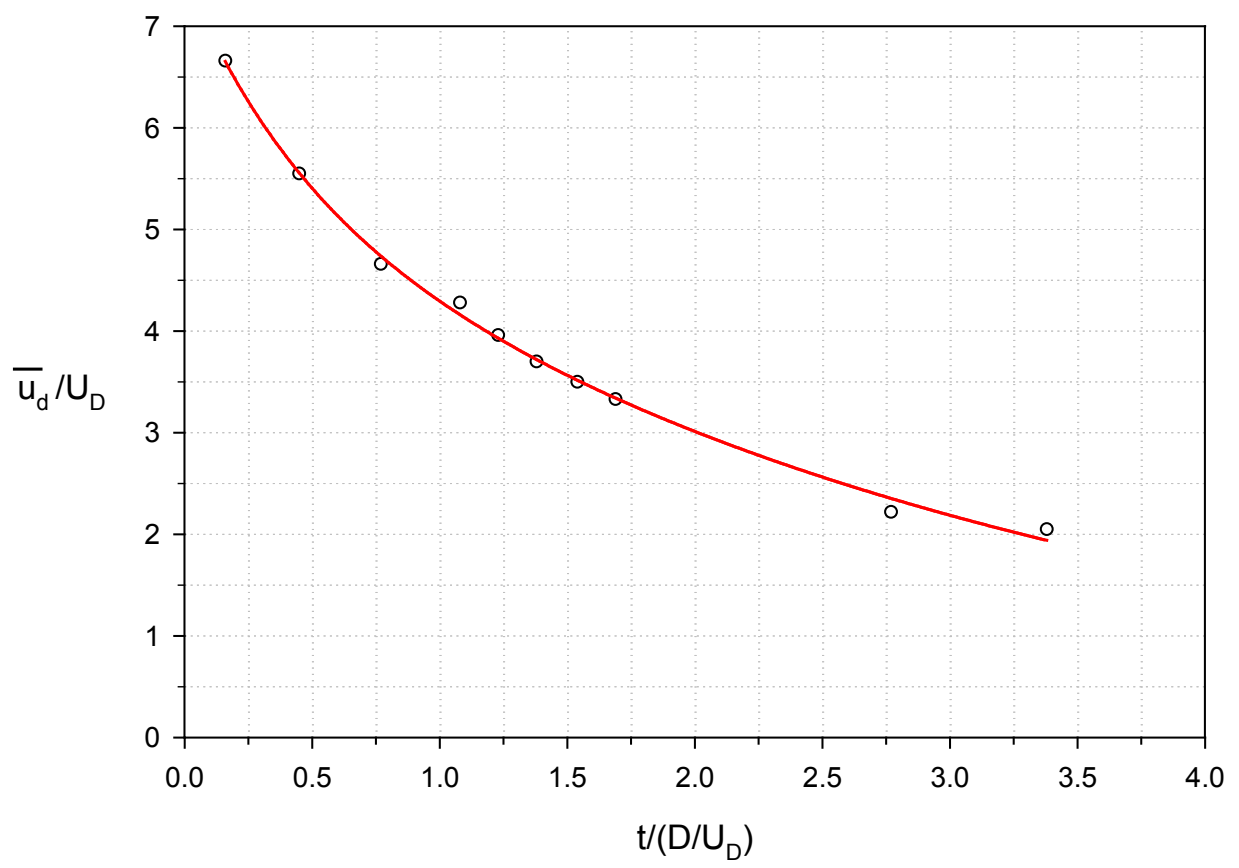

Figure 28.-Time evolution of average ejected droplets velocities (external observer reference). Droplet incident velocity $U_{i}=60 \mathrm{~m} / \mathrm{s}$, droplet diameter $d=4 \mathrm{~mm}$, water film thickness $\sim 10 \mu \mathrm{m}$

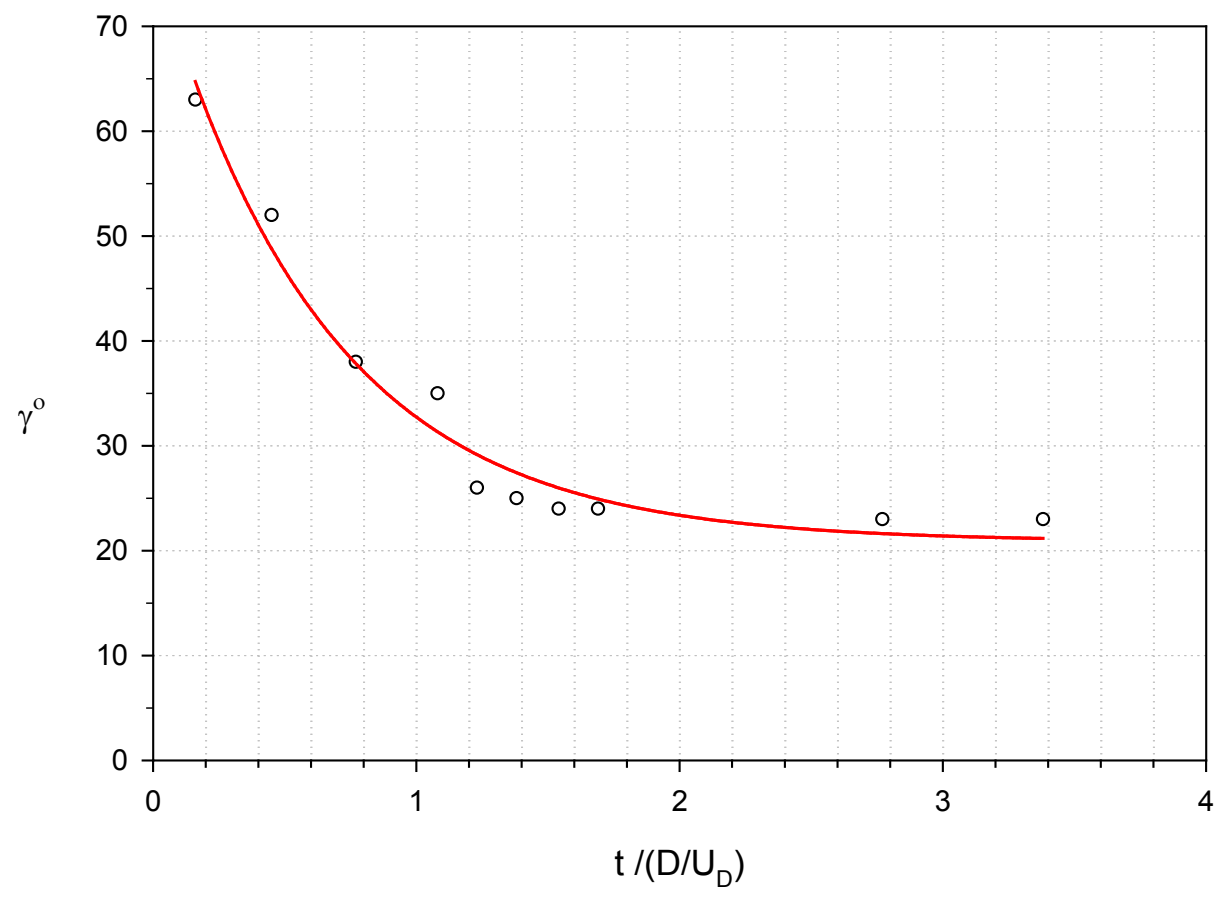

Figure 29.-Time evolution of averaged ejected droplets angle (external observer reference). Droplet incident velocity $U_{i}=60 \mathrm{~m} / \mathrm{s}$, droplet diameter $d=4 \mathrm{~mm}$, water film thickness $\sim 10 \mu \mathrm{m}$ 


\subsection{Concluding Remarks}

An existing small Rotating Facility was developed for studies on deformation/breakup and impact of water droplets induced by aerodynamic surfaces. Literature review has shown that there exists a large amount of information on droplet's deformation /breakup and impacts of different disturbance types but they do not apply to cases induced by aerodynamic surfaces in flight conditions. For these cases a Rotating Facility offer an appropriate experimental setup. The following are the main observations about the facility and its development:

- A Rotating Arm facility was developed at INTA. The recent main improvements are the increase of the arm's length, the power of the drive unit and structural strength and stability to allow model velocities up to $90 \mathrm{~m} / \mathrm{s}$ and model dimension of the order of $0.5 \mathrm{~m}$. The single droplet size range was extended to $100 \mu \mathrm{m}$ from an initial range of 1 to $4 \mathrm{~mm}$.

- The room where the Rotating Arm is housed was also increased in size to minimize wall interference effects that are larger at high velocities. The ceiling supports a structure to attach a droplet generator system and allow to release droplets at any location along the circumference and also installation of additional instrumentation that might be needed for different applications.

- The model design and manufacture become one of the critical issues in the facility because the model must be have a low mass to minimize the centrifugal forces and at the same time have enough strength to support high accelerations.

- High-speed imaging visualization for parameter measurement and qualitative observations has proved to be decisive for understanding the droplet physical processes. Shadowgraphs of single images, using double or triple exposure or high-speed video has been successfully adapted in the facility. Simultaneous shadowgraphs with conventional backlight photography to obtain another out of plane view, has been implemented for one particular case (perpendicular impacts).

- Non-intrusive Laser instrumentation such as Particle Image Velocimetry (PIV) or Laser Doppler Anemometry (LDA) can be implemented for air facility calibrations or other general air measurements. Also Phase Doppler Particle Analyzer(PDPA) has been used for droplet size calibration complemented with shadow images.

- Several measurement samples for a number of cases have been presented to highlight some of the facility capabilities. The main results from these cases are:

- Calibration of the air velocity for an aerodynamic model with an airfoil section of $0.199 \mathrm{~m}$ chord and velocity of $90 \mathrm{~m} / \mathrm{s}$. This represents a model chord $(c) /$ arm radius $(R)$ of approximately 0.1 (10 percent). Comparison of air velocity on the stagnation line with wind tunnel results has shown small differences from the leading edge up to a quarter of the chord and differences of the order of 2 percent up to 1.25 chords. This means that corrections that might be needed, depending on the specific application for this particular case, are expected to be small. However, for models with higher $(c / R)$ new calibration measurements must be made to estimate appropriate corrections or adequate actions needed, that will depend on test requirements.

- Droplet deformation/breakup characteristics. These measurements were obtained with the model of Reference 26 at $90 \mathrm{~m} / \mathrm{s}$ and $0.47 \mathrm{~m}$ chord. The deformation studies correspond to droplets of $490 \mu \mathrm{m}$ that start as spherical shapes and end up as flattened disks. This takes place at a small but constant distortion rate in both spheroid axis along the stagnation streamline at distances from the leading edge that go from 20 to 3 percent of the airfoil chord and having relatively long droplet residence times that are about two orders of magnitude larger than the droplet characteristic time defined by $(d / U)$. The breakup stage that follows the distortion is separated in two parts. The first part is one with extreme distortion, showing signs that the liquid inside has larger motions than it had in the deformation stage and distortion shape rates that are also larger than before, at distances from the leading edge from about 3 to 1.5 percent of the chord and residence time of only one order of magnitude larger than the droplet characteristic time $(d / U)$. The second part is the disintegration into water filaments and secondary droplets. It has been observed in experiments when the droplets are very near the surface, in the same conditions as in the first part but with diameters of $250 \mu \mathrm{m}$, droplets disintegrate at distances from the leading edge that are about 1.5 percent of the chord and the time to reach the surface is still an order of magnitude larger than $(d / U)$, with the observation that water filaments were not fragmented when the filaments touched the surface and therefore it could be said that complete disintegration had not yet been achieved.

- Droplet impacts for low and perpendicular incidences. Experiments have been presented for very large droplets of $4 \mathrm{~mm}$ diameters at $60 \mathrm{~m} / \mathrm{s}$ impacting on a small flat plate at zero incidence simulating a $4^{\circ}$ incidence and on an axially symmetric body with a flat surface facing the flow. The low incidence splash takes place in times that are of the order of the diameter over the normal velocity of impact, with measured ejected droplets mean diameters of about $20 \mu \mathrm{m}$ at the beginning of the splash and $100 \mu \mathrm{m}$ at the end. For the perpendicular case the splash takes place in times that are of the same order of magnitude as the droplet characteristic time $(d / U)$ and the ejected droplet dimensions have been estimated from velocities in the images to be a mean value of $5 \mu \mathrm{m}$ at the initial steps of the splash to $20 \mu \mathrm{m}$ at the end. 


\section{References}

1. Tan, J., Papadakis, M. and Sampath, M.K., "Computational Study of Large Droplet Breakup in the Vicinity of an Airfoil," DOT/FAA/AR-05/42, Final Report, October 2005.

2. Engel, O.G., "Fragmentation of Waterdrops in the Zone Behind an Air Shock," Journal of Research of the National Bureau of Standards, Vol. 60, No. 3, March 1958, pp. 245280.

3. Hanson, A.R., Domich, E.G. and Adams, H.S., "Shock Tube Investigation of the Breakup of Drops by Air Blasts," Physics. Fluids, Vol. 6, No.8, August 1963, pp.1070-1080.

4. Haas, F.C., "Stability of Droplets Suddenly Exposed to a High Velocity Gas Stream," AIChEJ, Vol. 10, No. 6, November 1964, pp. 920-924.

5. Ranger, A.A. and Nicholls, J.A. "The Aerodynamic Shattering of Liquid Drops," AIAA Journal, Vol. 7, February 1969, pp. 285-290.

6. Reinecke, W.G. and McKay, W.L. "Experiments on Waterdrop Breakup Behind Mach 3 to 12 Shocks," Sandia Corp. Report SC-CR-70-6063, 1969.

7. Reinecke, W.G. and Waldman, G.D.A., "Study of Drop Breakup Behind Strong Shocks with Applications to Flight," Avco Report AVSD-0110-70-77, May 1970.

8. Simpkins P.G. and Bales, L., "Water-Drop Response to Sudden Acceleration," Journal of Fluid Mechanics, Vol. 55, Part 4, 1972.

9. Gel'fand, B.E. Gubin, S.A. and Kogarko, S.M., "Various Forms of Drop Fractionation in Shock-Waves and their Special Characteristics," Inzhenemo-Fizicheski Zhurnal, Vol. 27, No. 1, pp. 119-126, July 1974.

10. Wierzba, A. and Takayama, K., "Experimental Investigation of the Aerodynamic Breakup of Liquid Drops," AIAA Journal, Vol. 26, No. 11, November 1988, pp. 1329-1335.

11. Hsiang, L.P. And Faeth, G.M., "Secondary Drop Breakup in the Deformation Regime," AIAA 92-0110, January 1992.

12. Hiroshara, H. and Kawahashi, M., "Experimental Investigation of Viscous Effects Upon a Breakup of Droplets in High-Speed Airflow," Experiments in Fluids 13, 1992, pp. 423-428.

13. Krzeczkowski, S.A., "Measurement of Liquid Droplet Disintegration Mechanism," Int. J. Multiphase Flow, Vol. 6, 1980, pp. 227-239.

14. Wierzba, A., "Deformation and Breakup of Liquid Drops in a Gas Stream at Nearly Critical Weber Numbers," Experiments in Fluids 9, 1990, pp. 59-64.

15. Kennedy, J.B. and Roberts, J., "Rain Ingestion in a Gas Turbine Engine," ILASS-AMERICAS Inst. of Liquid Atomization and Spray Systems, 4th Annual Conference, Hartford CT, USA, 1990, pp. 154-186.

16. Suzuki, T. and Mitachi, K., "Experimental Study on Aerodynamic Breakup of Liquid Droplets in TimeDependent Relative Velocity Field," 8th. Int. Conf. Liquid Atomization and Spray Systems, Pasadena CA, July 2000.
17. Miller, D.R., Lynch, C.J. and Tate, P.A., "Overview of High-Speed Close-Up Imaging in an Icing Environment," AIAA-2004-0407.

18. Tan, S.C., Papadakis, M., Miller, D., Bencic, T., Tate, P. and Laun, M.C., "Experimental Study of Large Droplet Splashing and Breakup," AIAA 2007-904.

19. Wright, W. and Potapczuk, M., "Semi-Empirical Modeling of SLD Physics," NASA/TM-2004-212916.April 2004.

20. Mundo, C., Sommerfeld, M. and Tropea, C., "Droplet Wall Collisions: Experimental Studies of the Deformation and Breakup Process," Int. J. Multiphase Flow, Vol. 21, No. 2, pp.151-173, 1995.

21. Sammenfink, W., Elsaber, A., Dullenkopf, K. and Wittig, S., "Droplet Interaction with Shear Driven Liquid Films: Analysis of Deposition and Secondary Droplet Characteristics," Int. J. Of Heat and Fluid Flow, Vol.20, pp.462-469, 1999.

22. Hammond, D.W., Quero, M., Ivey, P., Miller, D., Purvis, R., McGregor, O. and Tan, J., "Analysis and Experimental Aspects of the Impact of Supercooled Water Droplets into Thin Water Films," AIAA 2005-77.

23. Feo, A., "Rotating Arms Applied to Studies of Single Angular Drop Impacts," AIAA 87- 0257, January 1987.

24. Feo, A., "Effect of Heavy Rainfall on Aircraft Performance," Von Karman Institute of Fluid Dynamics Lecture Series "Effect of Icing, De-icing and Heavy Rain on Aircraft Performance”, February 1997.

25. Feo, A., "Experiments of a Perpendicular Waterdrop Impact in the Vicinity of an Air Stagnation Point," ILLASS Conference on Liquid Atomization and Spray Systems, Toulouse, France 1999.

26. Vargas, M. and Feo, A., "Experimental Observations on the Deformation and Breakup of Water Droplets Near the Leading Edge of an Airfoil," NASA/TM-2011-216946, AIAA Paper 2010-7670, August 2010.

27. Sor, S., "Potenciación del Brazo Rotatorio," AE-TNO 4420-287 INTA-10.Noviembre 2010.

28. "TSI Aerometrics MDG-100 Monosize Droplet Generator Instruction Manual," P/N 1990870, June 2002.

29. Jarillo, E., “Estudio Mediante Técnica Laser PDPA de la Formación de Gotas en el Generador de Gotas Monodisperso Aerometrics MDG-100," AE/TNO/4420/ 119/INTA-06, Marzo 2006.

30. Jarillo, E., "Medidas de Velocidad en Línea de Remanso de un Perfil en Túnel de Viento mediante LDV," AE-TNO 4420-124-INTA-09, Marzo 2009.

31. Sor, S. and García-Magariño, A., "PIV Measurements on Airfoil Model in Rotating Arm," AE-TNO-4420-091 INTA-11, Febrero 2011.

32. Feo, A., "High-Speed Shadowgraphs of a Single Drop Perpendicular Splash," Tech. Note N/221/510/87.017, INTA, November 1987.

33. Feo, A., "Waterdrop Splashback Characteristics of a Perpendicular Impact Near an Air Stagnation Point," Tech. Note N/221/501/89.025, INTA, October 1989. 



\section{Appendix.-Definitions and Abbreviations}

$\begin{array}{ll}a_{d} & \text { droplet acceleration } \\ \mathrm{c} & \text { characteristic body length } \\ d & \text { droplet diameter } \\ d_{e} & \text { equivalent droplet diameter } \\ d_{l} & \text { droplet dimension along minor axis (horizontal) } \\ d_{2} & \text { droplet dimension along major axis (vertical) } \\ f_{R} & \text { Raleigh frequencies } \\ h & \text { water film thickness } \\ h_{1} & \text { water film thickness upstream of splash } \\ t_{d} & \text { droplet travel time to the body } \\ t_{s} & \text { splashing process time } \\ u_{d} & \text { average velocity of ejected droplets } \\ u_{d t} & \text { average tangential velocity of ejected droplets } \\ u_{d n} & \text { average normal velocity of ejected droplets } \\ x_{d} & \text { distance from the droplet to the body } \\ \text { Bo } & \text { Bond Number } \\ C & \text { resultant body characteristics } \\ \text { CCD } & \text { charge-coupled device } \\ D & \text { Diameter of impact droplet } \\ D_{j} & \text { water jet diameter } \\ H & \text { crown wall height } \\ \text { LDV } & \text { Laser Doppler Velocimetry } \\ \text { PDPA } & \text { Phase Doppler Particle Analyzer }\end{array}$

PIV Particle Image Velocimetry

Re Reynolds Number

$U \quad$ incoming air velocity (free stream velocity)

$U_{a} \quad$ air velocity

$U_{d} \quad$ droplet velocity

$U_{d r} \quad$ relative air/droplet velocity

$U_{h} \quad$ Water film velocity

$U_{i} \quad$ impact velocity

$U_{j} \quad$ water jet exit velocity

$V_{D} \quad$ velocity magnitude of impact droplet

$V_{D n} \quad$ normal component of velocity of impact droplet

$W \quad$ crater width

We Weber Number

$\beta \quad$ incident angle

$\delta_{r} \quad$ surface roughness

$\gamma \quad$ ejecta angle

$\mu \quad$ air viscosity coefficient

$\mu_{w} \quad$ water viscosity coefficient

$\rho \quad$ air density

$\rho_{w} \quad$ water density

$\theta \quad$ water/surface contact angle

$\sigma_{w / a} \quad$ water/air surface tension 


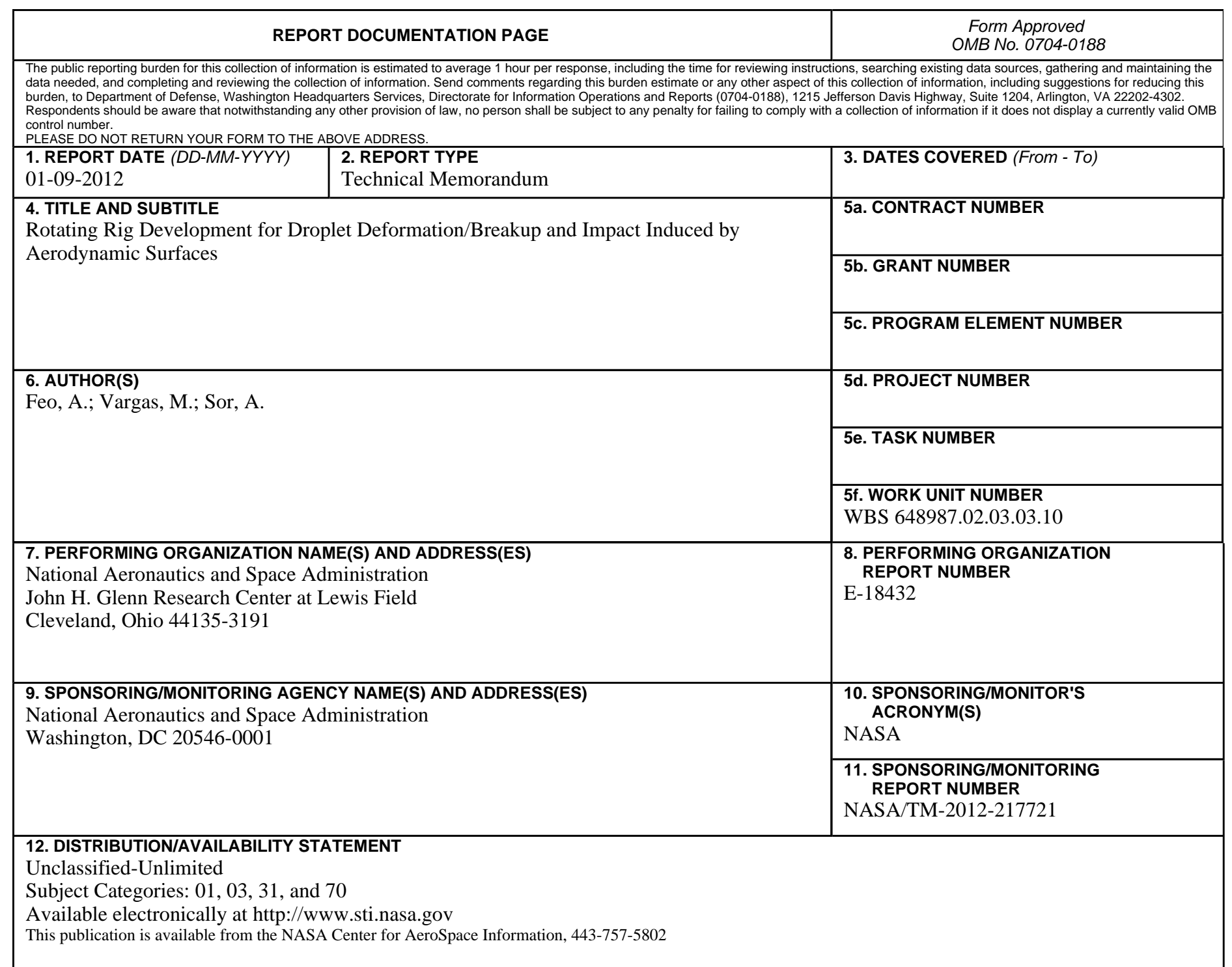

\section{SUPPLEMENTARY NOTES}

\section{ABSTRACT}

This work presents the development of a Rotating Rig Facility by the Instituto Nacional de Técnica Aeroespacial (INTA) in cooperation with the NASA Glenn Research Center. The facility is located at the INTA installations near Madrid, Spain. It has been designed to study the deformation, breakup and impact of large droplets induced by aerodynamic bodies. The importance of these physical phenomena is related to the effects of Supercooled Large Droplets in icing clouds on the impinging efficiency of the droplets on the body, that may change should these phenomena not be taken into account. The important variables and the similarity parameters that enter in this problem are presented. The facility's components are described and some possible set-ups are explained. Application examples from past experiments are presented in order to indicate the capabilities of the new facility.

\section{SUBJECT TERMS}

Aircraft icing; Aircraft safety; Aircraft control; Accident prevention; NASA programs

\begin{tabular}{|c|c|c|c|c|c|}
\hline \multicolumn{3}{|c|}{ 16. SECURITY CLASSIFICATION OF: } & \multirow{2}{*}{$\begin{array}{l}\text { 17. LIMITATION OF } \\
\text { ABSTRACT } \\
\text { UU }\end{array}$} & \multirow{2}{*}{$\begin{array}{l}\text { 18. NUMBER } \\
\text { OF } \\
\text { PAGES } \\
34\end{array}$} & \multirow{2}{*}{$\begin{array}{l}\text { 19a. NAME OF RESPONSIBLE PERSON } \\
\text { STI Help Desk (email:help@sti.nasa.gov) } \\
\text { 19b. TELEPHONE NUMBER (include area code) } \\
\text { 443-757-5802 }\end{array}$} \\
\hline $\begin{array}{l}\text { a. REPORT } \\
\text { U }\end{array}$ & $\begin{array}{l}\text { b. ABSTRACT } \\
\text { U }\end{array}$ & $\begin{array}{l}\text { c. THIS } \\
\text { PAGE } \\
\text { U }\end{array}$ & & & \\
\hline
\end{tabular}



